\title{
Gap flows: Results from the Mesoscale Alpine Programme
}

\author{
Georg J. Mayr, ${ }^{\text {a* }}$ Laurence Armi, ${ }^{\mathrm{b}}$ Alexander Gohm, ${ }^{\mathrm{a}}$ Günther Zängl, ${ }^{\mathrm{c}}$ Dale R. Durran, ${ }^{\mathrm{d}}$ \\ Cyrille Flamant, ${ }^{\mathrm{e}}$ Saša Gaberšek, ${ }^{\mathrm{f}}$ Stephen Mobbs, ${ }^{\mathrm{g}}$ Andrew Ross ${ }^{\mathrm{g}}$ and Martin Weissmann ${ }^{\mathrm{h}}$ \\ ${ }^{a}$ Institute of Meteorology and Geophysics, University of Innsbruck, Austria \\ b Scripps Institution of Oceanography, La Jolla, USA \\ c Meteorologisches Institut der Universität München, Germany \\ ${ }^{\mathrm{d}}$ University of Washington, USA \\ e Institute Pierre Simon Laplace, Service d'Aéronomie, France \\ ${ }^{\mathrm{f}}$ University of Ljubljana, Slovenia \\ $\mathrm{g}$ University of Leeds, $U K$ \\ h Institut für Physik der Atmosphäre, DLR Oberpfaffenhofen, Germany
}

\begin{abstract}
An overview of advances in the observation, modelling, forecasting, and understanding of flows through gaps achieved in the Mesoscale Alpine Programme is given. Gaps are lateral constrictions of topography (level gaps) often combined with vertical terrain changes (passes). Of the possible flow configurations, only an asymmetric one (relatively deep and slow upstream, accelerating and thinning downstream), which connects two different 'reservoirs' on each side of the gap, is examined. The flow is strongly nonlinear, making hydraulics (reduced-gravity shallow-water theory) rather than linear theory the simplest conceptual model to describe gap flow. Results from idealized topographical and flow conditions are presented, together with gap flows through a pass in the central Alpine Wipp Valley. For a given depth of the upstream reservoir, the gap controls the mass flux through it and marks the transition from a subcritical flow state upstream to a supercritical one downstream, which eventually adjusts to the downstream 'reservoir' in a hydraulic jump. Three gap flow prototypes were found: a classical layer one with neutral stratification and a capping inversion and two with a continuous stratification, for which a special analytical self-similar hydraulic solution exists. In all three cases, a deepening wedge of nearly mixed and stagnant air forms on top of the gap flow plunging down from the pass. The descent causes a warming and (relative) drying of the air, making gap flows a special case of föhn. Topographical variations smaller than the gap scale cause additional hydraulic jumps, flow separation, vorticity banners, gravity waves, and interactions with cold pools. Turbulent friction cannot be neglected. The climatological frequency of gap flows depends on the establishment of two different reservoirs and reaches 20\% for the Wipp Valley. Copyright (c) 2007 Royal Meteorological Society
\end{abstract}

KEY WORDS mountain; constriction; hydraulics; föhn

Received 5 October 2006; Revised 2 January 2007; Accepted 19 February 2007

\section{Introduction}

Mountain ranges are rarely smooth ridges. They are crisscrossed by indentations of various depths as an example from the central Alps shows (Figure 1). Some of these gaps allow air to flow from one side to the other without having to detour over or around the mountain range. A gap is a lateral topographical constriction with a level bottom, as found in straits, or combined with a vertical constriction into a pass. The definition of the term 'gap wind' dates at least to Reed (1931). As cause, he invoked a venturi effect (i.e. highest wind speed at the narrowest section for continuity reasons) often combined with an ageostrophic pressure gradient parallel to the channel. However, for larger gaps, the flow continues to accelerate after the maximum constriction (e.g. Scorer, 1952), invalidating the venturi explanation. The resulting asymmetric flow configuration is visualized by the stratiform clouds

* Correspondence to: Georg J. Mayr, Institute of Meteorology and Geophysics, University of Innsbruck, Innrain 52, 6020 Innsbruck, Austria. E-mail: georg.mayr@uibk.ac.at capping the gap flow layer in Figure 2(a). A thick, relatively slowly moving layer on the upstream side becomes faster and thinner on the downstream side. If one zooms in to one of the gaps (Figure 2(b)), one can see the transition until the descent has gone below the lifting condensation level and the cloud has evaporated. Thus we will define gap flow as an asymmetric flow through a topographical constriction (lateral and/or vertical) driven by different 'reservoirs' of air or fluid on either side of the gap, with a deeper slowly moving layer on the upstream side and a thinner much faster layer downwind of the gap. Having a deeper upstream reservoir means having colder air there. Consequently, isentropes will be at a higher altitude than in the downstream reservoir and pressure values will be larger. In the AMS Glossary (American Meteorological Society, 1999), the pressure gradient is used to define gap flow. It will be appropriate to describe these flows and the pressure gradient within the framework of reduced-gravity hydraulics dating to Prandtl (1942) and first applied to gap flows by Scorer (1952). Although simple single-layer reduced-gravity hydraulics describes 


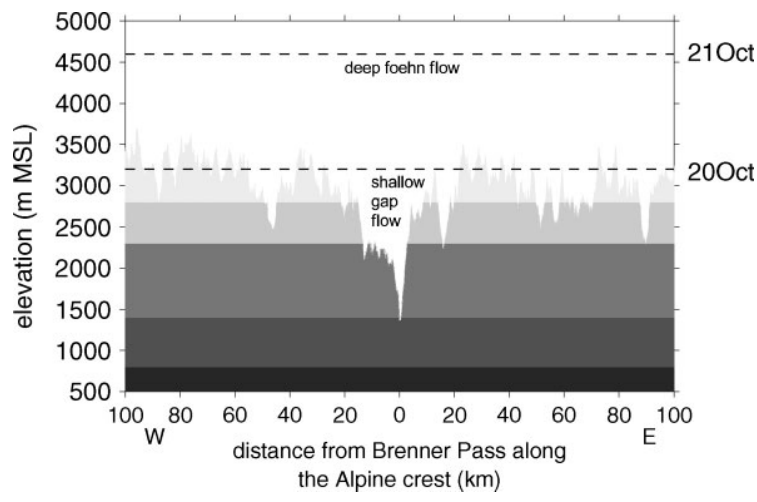

Figure 1. Main Alpine crest along the Austrian-Italian border viewed from the south (Italy). The deepest of the pronounced indentations is the triple gap of the Wipp Valley at the Brenner Pass. The grey shading accentuates the bottom of the three gaps at $1400 \mathrm{~m}, 2300 \mathrm{~m}$ and $2800 \mathrm{~m}$ amsl, respectively. The altitude of the top of the layer flowing from south to north indicates a shallow gap flow on 20 October 1999 and a deep föhn flow on the following day. Adapted from Armi and Mayr (2007).

the acceleration through the gap, for a full description of mountain flows through gaps it is necessary to include the effects of continuous stratification (Armi and
Mayr, 2007). Due to the descent on the downstream side combined with strong turbulent mixing, such gap flows often show the characteristics of föhn as defined by WMO (1992) and adopted here as a strong, gusty wind warmed and dried by descent, in general on the lee side of a mountain. The potential descent is naturally larger for passes than for level gaps. Many well-known föhn and downslope wind locations are downstream of a gap, e.g. Brenner Pass with the Wipp Valley and Innsbruck (Austria; e.g. Seibert, 1990), Furka and St. Gotthard Pass with the Reuss Valley (Switzerland), several passes that lead into the Rhine Valley (Switzerland; e.g. Richner et al., 2006), Vratnik Pass upstream of Senj (Croatian bora; e.g. Bajić, 1989), and Kearsage Pass with Onion Valley and Independence in the Owens Valley (USA; site of the Sierra Wave Project and the Terrain-induced Rotor Experiment; e.g. Holmboe and Klieforth, 1954).

When the upstream reservoir is deep enough to exceed the crest on either side of a gap, the mass flux going across the crest is large compared to the amount going through the gap (Figure 1) and 'deep föhn' (instead of 'deep gap flow') is the most suitable term. Especially with higher mountain ranges, the cold air reservoir might

(a)

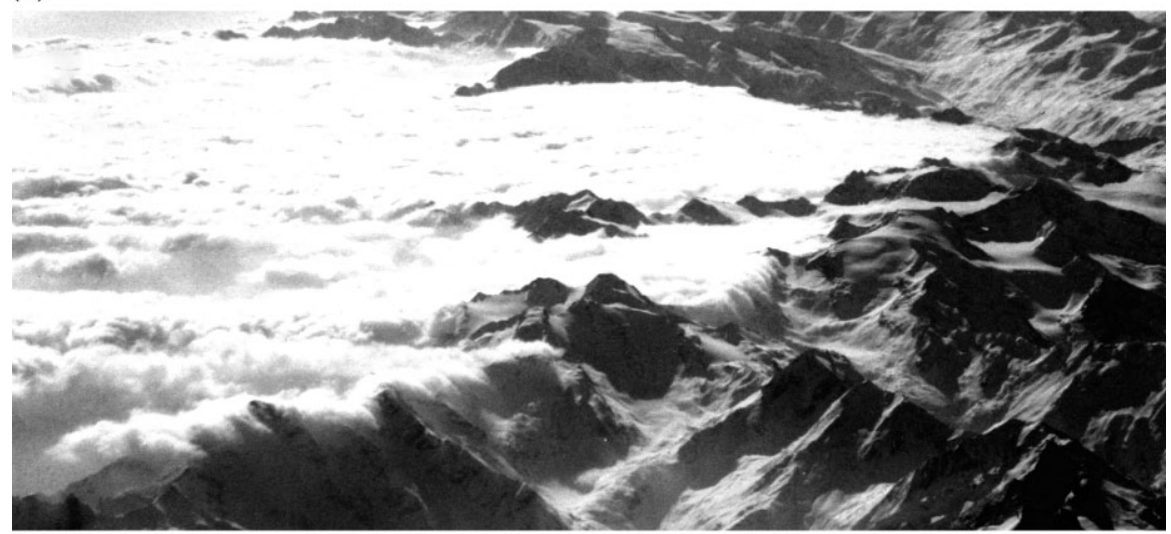

(b)

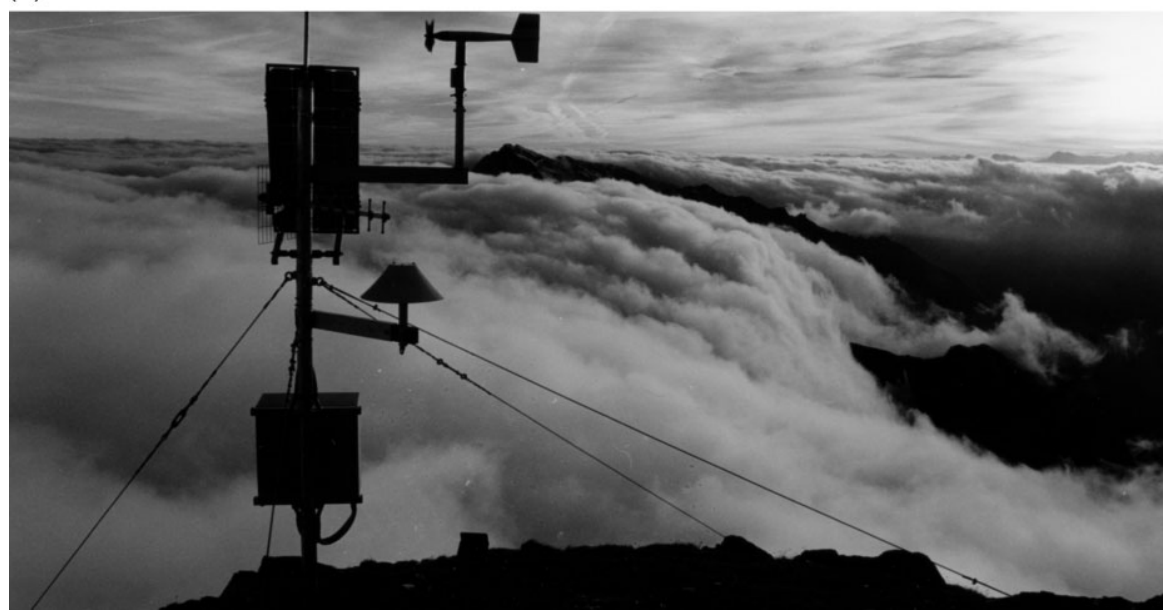

Figure 2. (a) View from the DLR-Falcon aircraft flying at the centre of the Wipp Valley, downstream of the pass, at a height of $7200 \mathrm{~m}$ amsl looking to the south-west. The top of the cloud layer, which rises slightly towards the Alpine crest, marks the top of the upstream gap flow. (b) Close-up of gap flow layer ('cloud fall') descending into the Wipp Valley with evaporating clouds as viewed westwards from a mountain top at the eastern edge of Brenner Pass. Photographs: Johannes Vergeiner (from Vergeiner, 2004). 
be lower than the crest and thus completely blocked if it were not for indentations in the crest through which the air flows. This is termed 'shallow gap flow' and is depicted in Figure 1. Before the advent of gap flow dynamics, this type of flow was known as 'shallow föhn' in the Alps (Kanitscheider, 1932). Compared to flow over and around mountain ranges, the body of literature on flows 'through' mountain ranges is small. One of the first descriptions is Hurd (1929) for a flow of cold air through a gap in the Mexican Sierra Madre. The largest body of literature exists for the northern Pacific coast of North America (e.g. Cameron, 1931; Cameron and Carpenter, 1936; Colman and Dierking, 1992; Jackson and Steyn, 1994a,b; Colle and Mass, 1998), where strong cooling over the wintertime continent provides a persistent cold upstream reservoir and the relatively mild coastal air the downstream reservoir. Most of the works there and in other regions of the world (e.g. Scorer, 1952; Pettre, 1982) focused on almost level gaps. Pan and Smith (1999) summarize most of the gap flow studies prior to the Mesoscale Alpine Programme (MAP). MAP was the first international field program with an explicit goal of studying gap flows, selecting the central Alpine Wipp Valley as target area (Mayr et al., 2004; Volkert and Gutermann, 2007). The scientific goals were inspired by recent previous work in the atmosphere (Colle and Mass, 1998) and the ocean (Farmer and Armi, 1999). The aims were to study the combined effects of a lateral and vertical topographic constriction in a situation of continuous stratification, and to examine the interaction between deep föhn across the crest with the underlying flow through the gap. Through an international pooling of observational resources, a spatially highly resolved dataset was to be created.

This paper attempts to summarize and digest the gap flow results of MAP. Its structure is as follows: We start (Section 2) with a description of gap flows under highly idealized assumptions about the shape of the topography and the air masses involved to expand upon the key ingredients of gap flows introduced above. Gap flows in a realistic topographical setting (Wipp Valley) and the results from MAP are discussed in Section 3. Section 4 looks at requirements for the observation and numerical simulation of gap flows, and Section 5 provides conclusions.

\section{Idealized studies}

Apart from field campaigns, the three methods to study flow over and around complex terrain have traditionally been linear theory, reduced-gravity shallow-water theory ('hydraulic' theory) and numerical simulations. Linearization of the governing equations and the lower boundary condition fails to describe gap flows as shown by Pan and Smith (1999). In linear theory (e.g. Queney, 1948; Klemp and Lilly, 1975; Smith, 1979, 1980) vertically propagating gravity waves cause lower pressure and accelerating winds on the lee slopes of a mountain ridge; their strength is proportional to the height of the mountain. Accordingly, the strongest pressure anomaly occurs along the lee slopes of the mountains on either side of the gap and not in the gap itself, even when confluence at the gap entrance is included in a fully three-dimensional (3D) version of linear theory (Pan and Smith, 1999; Zängl, 2002c). Linearized gap flows are always weaker than the flow down the adjacent crests, contrary to what is often observed.

Numerical simulations solving the complete set of nonlinear governing equations are useful because they permit sensitivity studies and the identificaton of crucial mechanisms behind a phenomenon by proceeding from nature-like simulations to highly idealized settings. One of the key parameters for gap flows is the shape of the underlying topography. With a geostrophically balanced frictionless background with uniform static stability flowing parallel to an infinite ridge, Zängl (2002a) found flow towards lower pressure as in Sprenger and Schär (2001). An isolated ridge, however, reverses the direction. It splits the flow on its upwind edge, leading to anticyclonic flow on the left side (looking in the flow direction) of the isolated ridge. This flow has an ageostrophic component directed towards the mountain, thus counteracting and slightly overpowering the larger-scale geostrophic pressure gradient.

Since gap flows are confined by the local terrain and their typical depth is of comparable magnitude to the depth of the planetary boundary layer, turbulent friction must not be neglected. Adding friction causes a counterclockwise turning of the low-level wind compared to the flow aloft. This adds a wind component directed towards the region of lower large-scale pressure. The flow through the gap is for realistic values of the roughness length always directed towards the side of the mountain range with the lower large-scale pressure (Zängl, 2002a; Gaberšek and Durran, 2006). Friction can also decouple the low-level flow from the flow aloft by means of a weak stable layer between the two flows (Gaberšek and Durran, 2006). While the relative speed-up in the case with a lee wave is higher over the adjacent lee slopes than through the gap, gap flow accelerations are stronger for the situation with upstream blocking (Gaberšek and Durran, 2006). Gaberšek and Durran (2006) quantitatively demonstrated the importance of friction by volume-averaged momentum-flux budgets.

For background flows with a component perpendicular to the obstacle, Zängl (2002a) identified the pressure difference across the gap as the main driving force for the acceleration of gap flow. Gaberšek and Durran (2004) found substantial additional accelerations produced by downward momentum fluxes (with values slightly larger than from the pressure gradient force) near the gap exit when significant lee waves were present or by lateral momentum flux convergence near the gap entrance when there was significant upstream blocking. The transition from the lee wave regime to upstream blocking was produced by increasing the upstream values of the nondimensional mountain height, $\mathrm{NH} / \mathrm{U}$ (where $\mathrm{N}$ is the 
Brunt-Väisälä frequency, $\mathrm{H}$ is the mountain height and $\mathrm{U}$ the mean wind speed). The disagreement over the importance of convergence at the gap entrance between the studies of Gaberšek and Durran (2004) and Zängl (2002a,c) might be partly due to the shape of the gap.

Friction along the sidewalls of the gap and channel will generate a couplet of potential vorticity (PV) banners of opposite sign (Ross and Vosper, 2003). Other possibilities are through flow splitting and gravity wave breaking. Simple scaling (Ross and Vosper, 2003) estimates the magnitude of the PV generated in such a way to be of the order of $10 \mathrm{pvu}$ (potential vorticity unit = $10^{-6} \mathrm{~K} \mathrm{~m}^{2} \mathrm{~kg}^{-1} \mathrm{~s}^{-1}$ ). $\mathrm{PV}$ is advected away from the gap. Due to its conservative nature, it can persist for dozens and hundreds of kilometres away from the gap (Grubišić and Cardon, 2002; Gohm and Mayr, 2005). PV banners from adjacent gaps in the mountain range will then merge into a single banner (Schär et al., 2003; Gohm and Mayr, 2005). At locations of flow separation and hydraulic jumps, the PV will be advected away from the surface (Ross and Vosper, 2003).

Hydraulic theory is the third mainstay of idealized mountain flow studies with pioneering work by Prandtl (1942) and Long $(1953,1954)$. While it shares with linear theory the desirable characterisitc of being analytically tractable at least for special cases, it is fully nonlinear, a key characteristic of asymmetric gap flows. The main idealization is in assuming steady state and taking integral averages of air/fluid properties in the vertical, e.g. constant potential temperature for air and constant density for a fluid, respectively. In the most strongly idealized case there is a single flowing layer with an inert layer of different potential temperature (density) on top. This special case is termed 'single-layer hydraulics'. Further assumptions are for the flow to be hydrostatic and incompressible in the integrated layer. The equations can also be solved numerically when more complicated topography is included (e.g. Schär and Smith, 1993; Pan and Smith, 1999). Internal gravity waves may form along the top of the hydraulic layer. Their speed, $\sqrt{g^{\prime} h}$, relative to that of the fluid/air, $U$, can be expressed by the Froude number $F r^{2}=U^{2} /\left(g^{\prime} h\right)$, where $g^{\prime}$ is reduced gravity and $h$ the fluid/air depth of the layer. Long (1954) showed that the asymmetrical case of a relatively slow and thick subcritical (i.e. $F r<1$ ) layer transitioning at the crest of a 2D ridge into a supercritical $(F r>1)$, relatively fast and thin state happens for a crest height of $M_{\mathrm{c}}=1+0.5 F r^{2}-1.5 F r^{2 / 3}$. Not only vertical constrictions formed by the rise of the terrain, but also lateral constrictions (i.e. level gaps) may cause the flow to transition from a subcritical to a supercritical state (Arakawa, 1969). For a channel with vertical walls, a lateral narrowing (ratio to its upstream width $W<1$ ) reduces the vertical narrowing via a rise of the terrain that is required to render the flow supercritical:

$$
M_{\mathrm{c}}=1+\frac{1}{2} F r^{2}-\frac{3}{2}\left(\frac{F r}{W}\right)^{2 / 3}
$$

Nature provides the whole spectrum of level gaps with lateral constrictions only, such as straits (e.g. Reed, 1931; Scorer, 1952; Dorman et al., 1995; Colle and Mass, 2000) and valleys and fjords (e.g. Pettre, 1982; Jackson and Steyn, 1994b; Zängl, 2004) and gorges (e.g. Cameron, 1931), as well as a combination of lateral and vertical constrictions (i.e. passes; e.g. Arakawa, 1969; Colle and Mass, 1998; Gohm and Mayr, 2004, 2005; Mobbs et al., 2005). Idealized and realistic simulations with a numerical hydraulic model (Pan and Smith, 1999; Gohm et al., 2004) found the effect of the rising terrain to dominate over the confluence caused by lateral constriction.

The depth of the single-layer subcritical flow will have decreased by one third of its far upstream value by the time it reaches the narrowest part. This follows directly from the Bernoulli equation and the transition to a supercritical state at the narrowest part, where the speed of the interfacial gravity wave equals the speed of the fluid/air. This location is termed 'control' since for a given depth of the fluid only one flow rate is possible.

Since gap flows are often not well mixed on the upstream side, hydraulic solutions for continuous stratification are of particular interest. Analytical solutions are feasible under the assumption of neutrally stratified fluid above the gap flow. Long's (1955) seminal laboratory and analytical studies found an accelerated flow passing over the crest of an obstacle and descending as a jet beneath a slow recirculation zone. Smith (1985) developed a special solution of Long's equation for continuously stratified, uniform-speed far-upstream flow by prescribing a stagnant wedge of air above the downslope, ahead of which the streamlines split. Durran and Klemp (1987, their Figure 8) and Farmer and Armi (1999, their Figure 3 ) showed that this flow configuration, despite its continuous stratification, is qualitatively similar to the one for single-layer hydraulic flow, especially when the depth of the continuously stratified system is less than one half of its vertical wavelength (Durran and Klemp, 1987). Wood (1968) derived an analytical solution with the constraint of self-similar flow through a level gap (instead of across a ridge) with different air masses on the two sides. The flow is self-similar in the sense that, at any position, the density and velocity profiles can be scaled with the height of the moving stratified layer. As the flow accelerates from the upstream reservoir towards and through the gap, stagnant, nearly neutrally stratified layers form both aloft and near the surface. These layers isolate the flow from below and above. Armi and Williams (1993) reproduced the streamline splitting in the laboratory. Armi and Mayr (2007) first observed gap flow showing the characteristics of Wood's solution in the atmosphere.

\section{Realistic settings}

Gap flows have been observed in many different settings all over the world. The most densely instrumented 
field campaign so far took place as the GAP project of MAP (project P4) in the central part of the Alps (Section 3.1). Details of the project including instrumentation, gap flow periods, special observations periods, and instrumentation are described in Mayr et al. (2004). The topographical setting of the Wipp Valley and its flowrelevant parameters are outlined in Section 3.1. The following aspects are explored in more detail: prototypes of shallow and deep gap flow (Section 3.2), the role of small-scale topography (Section 3.3), and a discussion why gap flow descends the lee slope (Section 3.4). How frequently gap flows occur and how they can be forecast are discussed in Sections 3.5 and 3.6, respectively.

\subsection{Topography of the Wipp Valley in the central Alps}

The north-south extent of the Alps is largest in their central part (Figure 3). A valley leads from the southern rim of the Alps for $220 \mathrm{~km}$ to the lowest pass of the central Alps, the Brenner Pass. The Wipp Valley continues northwards for $30 \mathrm{~km}$ while the altitude of the valley centre decreases by about $500 \mathrm{~m}$. The mouth of the Wipp Valley drops abruptly by an additional $200 \mathrm{~m}$ into the nearly perpendicular, west-east oriented Inn Valley, which drains into the northern Alpine foreland. A west-east oriented mountain range impedes the direct northward continuation of the flow. The gap at the Brenner has three parts delineated by different grey shadings in Figure 1: a middle one from 2.3 to $2.8 \mathrm{~km}$ amsl, whose base is $15 \mathrm{~km}$ wide, a lower proboscis-like part that extends down to $1.4 \mathrm{~km}$ amsl but is only about $1 \mathrm{~km}$ wide at its bottom, and an upper part from $2.8 \mathrm{~km}$ amsl to the average height of the surrounding Alpine crest of $3.2 \mathrm{~km}$, yielding a depth $\Delta H=900 \mathrm{~m}$ for the middle and upper gap. Both the lateral extent of the gap and the length of the northern Wipp Valley $(L=30 \mathrm{~km})$ are clearly less than the Rossby radius of deformation $L_{\mathrm{R}}=N \Delta H / f \approx 100 \mathrm{~km}$, with the Coriolis parameter $f=10^{-4} \mathrm{~s}^{-1}$. The Coriolis force plays only a negligible role: $U /(f L) \approx 1$ (cf. Flamant et al., 2002). Armi and Mayr (2007) noted that the narrowest part of the upper gaps is actually a few kilometres upstream (south) of the lowest gap (Figure 3). The cross-sectional area of the two upper parts is about 15 times larger than the lower gap, so that most of the mass flows through the upper gaps in the most common situations of the gap flow being deep enough to extend into these upper gaps. The terrain on the northern and southern sides of the gap is highly irregular and complex, in stark contrast to the smooth channels used in idealized studies. Which effective topography is 'felt' by the gap flow will depend on the depth of the flow. The effects that particular topographical irregularities have on the gap flow will be discussed in Section 3.3. During MAP, the Brenner section was instrumented for air flowing from south to north through the gap; 'upstream' is therefore south of the Alpine crest. Gap flow confined below the crest we will call 'shallow' (cf. Figure 1). 'Deep' gap flow is topped by and interacts with deep föhn flow aloft that crosses the crest. (a)

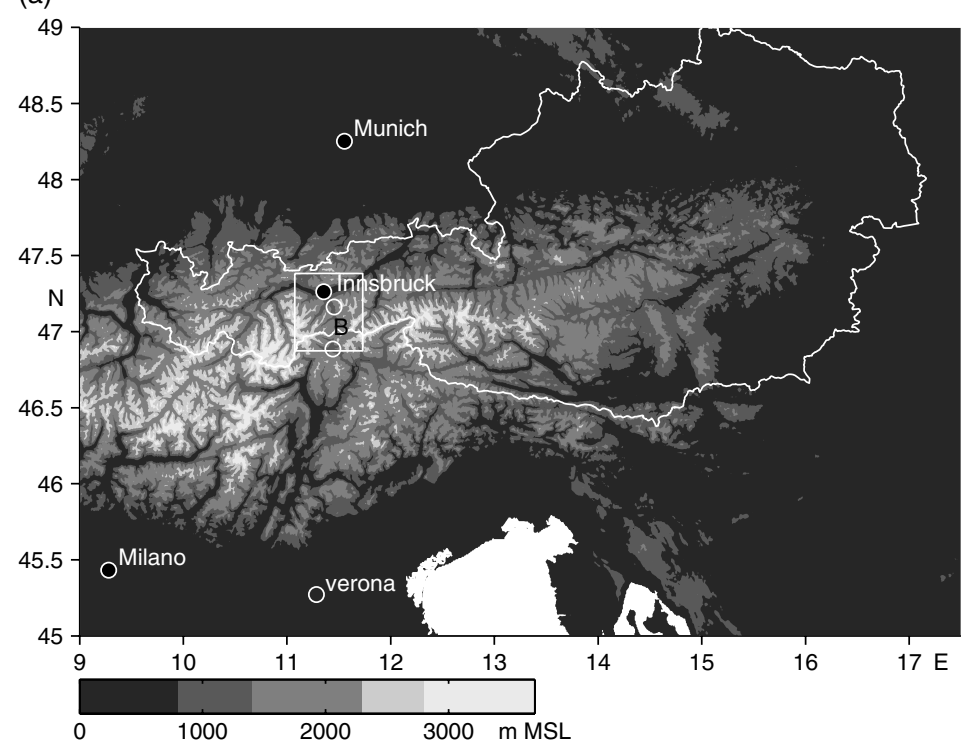

(b)

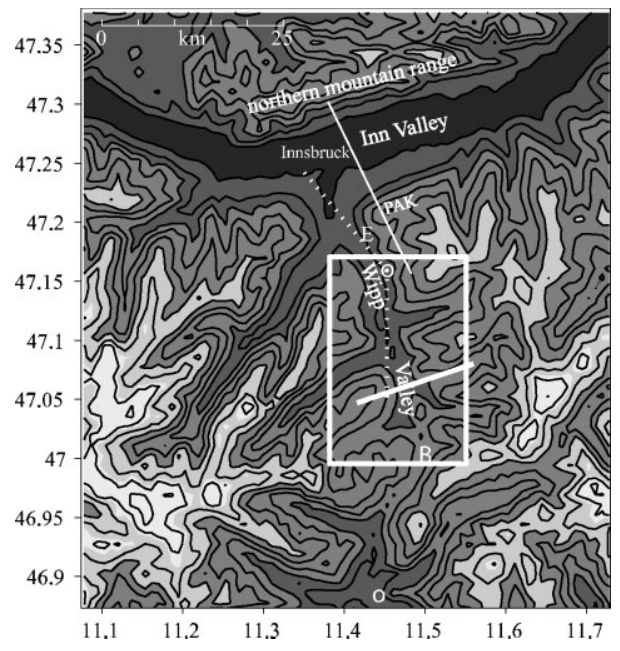

Figure 3. Topography of the central Alps. (a) shows MAP rawinsonde stations (open circles), the Austrian border, Brenner Pass (B), and a white frame indicating the region depicted in Figure 6; (b) shows a close-up with geographical features with the Patscherkofel summit (PAK), the location of the upstream and downstream radiosondes (see Figure 4), the föhn climatology and forecasting locations (Sections 3.5 and 3.6), the rectangle indicating the region of Doppler lidar radial velocities in Figure 7(b), the dotted lines depicting the vertical sections of lidar radial velocities in Figure 5, the (bold) across-valley line indicating the vertical section of aerosol reflectivity in Figure 7(a), and the (thin solid) valley-parallel line of the aerosol reflectivity cross-section in Figure 8. Elevation shading emphasizes the triple structure of the Brenner Pass (cf. Figure 1). Shading intervals are from darkest to lightest: lower than $800 \mathrm{~m}, 800-1400 \mathrm{~m}, 1400-2300 \mathrm{~m}$ (lower pass), 2300-2800 m (middle pass), and greater than $2800 \mathrm{~m}$ amsl (upper pass). The contours are every $300 \mathrm{~m}$ above $800 \mathrm{~m}$ amsl. 


\subsection{Shallow and deep gap flow in the Wipp Valley}

Armi and Mayr (2007) identified three prototypes of gap flow in the Wipp Valley: single-layer hydraulics flow upstream and downstream of the gap; a continuously stratified upstream flow (Wood's (1968) solution) transitioning into single-layer flow downstream, and a continuously stably stratified flow upstream and downstream. Their schematics are shown in Figure 4. The average across-valley topographical bottom height 'felt' by the flow is shown in Figure 4 (centre column).

On the upstream side, the classical single layer of nearly neutral stratification (Figure 4(a)) is bounded below by a blocked near-surface layer and capped and isolated from the flow aloft by a strong inversion, of the order of several K. Air is withdrawn from this upstream reservoir of the neutral layer up to the top of the inversion. It already starts descending upstream of the gap. The pass acts as a control where the Froude number is unity and a transition from subcritical to supercritical flow takes place. A hydraulic jump occurs at the indentation in the average topography downstream of the gap; the flow is decelerated and the isentropes sharply ascend. Here, the air from the middle gap reaches the valley bottom for the first time. Afterwards the flow accelerates and transits to supercritical again before it encounters another jump upstream of the downwind mountain range. The flow speeds up typically by about 50-100\%. An upper limit to the downslope speed can be estimated (cf. Armi and Mayr, 2007) from the descent $\Delta h$ of the capping inversion formed by a potential temperature step $\Delta \theta$, which results in a change of reduced pressure at the surface of

$$
\Delta p=g \rho \frac{\Delta \theta}{\theta_{0}} \Delta h,
$$

where $\theta_{0}$ is a reference potential temperature. With the Bernoulli equation along a stream surface (which to a good approximation is an isentropic surface), the increase from the upstream velocity $v_{\mathrm{u}}$ to its downstream value $v_{\mathrm{d}}$ is

$$
\left(\frac{v_{\mathrm{d}}}{v_{\mathrm{u}}}\right)^{2}=1-\frac{2 \Delta p}{\rho v_{\mathrm{u}}^{2}}=1-\frac{2 g \frac{\Delta \theta}{\theta_{0}} \Delta h}{v_{\mathrm{u}}^{2}} .
$$

This is an upper limit since turbulent friction is not included. Rotach and Zardi (2007) summarize the state of the art of the effects of turbulence in such highly complex terrain. The flow will speed up more for stronger capping inversions and for larger descents of the flow on the downstream side. The latter also depends on the underlying topography. When strong inversions are created upstream, e.g. by large air-sea temperature differences, speed-ups are large even for relatively small hills (Mobbs et al., 2005). Above the inversion, which separates the gap flow from the flow aloft, the isentropes are nearly horizontal and there is minimal or no flow across the crest. The descent of the inversion combined with wind-shear-induced turbulent detrainment on its top forms another nearly neutrally stratified layer as the flow progresses further downstream. The detrainment weakens the inversion. Farmer and Armi (1999) describe a modification of single-layer hydraulics necessitated by such a horizontally varying density step topping the flowing layer.

In contrast to the classical single-layer case, the flowing layer for the second type of shallow gap flow (Figure 4(b)) is not neutral but continuously stably stratified. A special analytical hydraulic solution (Wood, 1968, cf. Section 2) is valid for an arbitrary stability profile as long as the flowing layer is isolated below and aloft by neutral layers on the upstream side. For a linear stability profile shown in Figure 4(b), the velocity profile has a parabolic-like shape (cf. Wood, 1968; Armi and Williams, 1993; Armi and Mayr, 2007). In this second type of gap flow, the flow downstream of the gap is shallow enough that turbulent mixing in the boundary layer and hydraulic jump(s) can change the vertical stratification to (nearly) neutral and thus single-layer hydraulics. On top of this newly mixed layer, a new capping inversion topped by another (nearly) neutrally stratified and (nearly) stagnant layer has formed.

For the third prototype of gap flow (Figure 4(c)), the flowing layer is much deeper, continuously stably stratified and governed by Wood's (1968) solution on the upstream side of the gap. Only a fraction of the flow encounters the hydraulic jump near the pass so that the flow remains stably stratified all the way to the downwind mountain range. From the gap to the downwind mountain range, the nearly neutrally stratified and stagnant layer on top of the gap flow has become several times deeper than on the upstream side through descent of the gap flow layer and turbulent detrainment. This type of flow was encountered in the Wipp Valley during deep gap flow, where much more air flows across the crest than through the gap. Above the crest, however, there is no topography to provide the lateral constriction required for Wood's (1968) solution. Since a lateral topographical constriction causes a jet-like flow profile in the acrossgap direction, Armi and Mayr (2007) hypothesize that a pre-existing jet in the meso- $\alpha$-scale flow across the Alps assumes the role of the lateral topographical constriction for deep gap flows.

For the air mass differences and topography particular to the Wipp Valley, the first two types with singlelayer hydraulic flow downstream of the gap were found for shallow gap flow, and the completely continuously stratified third type only for deep föhn flow. A feature, which all three types share, is the formation of a thickening nearly neutral and stagnant layer on top of the gap flow, which decouples the latter and explains why hydraulic theory is a good approximation to the dynamics of gap flow. In situations where the flow becomes so deep that air up to or even beyond the tropopause crosses the crest (e.g. Zängl and Hornsteiner, 2007), flow modifications by gravity waves become substantial.

A gap not only affects the downstream flow but also the upstream reservoir. When flow through the gap starts, this information will spread upstream (Armi and Mayr, 

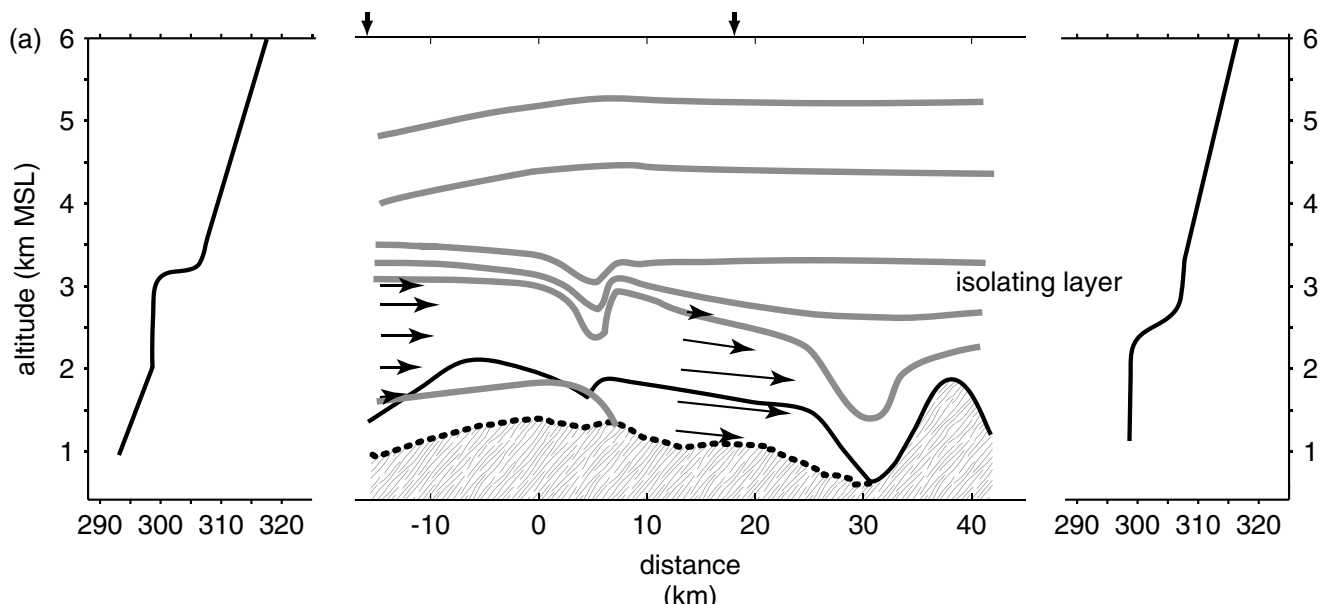

$(\mathrm{km})$

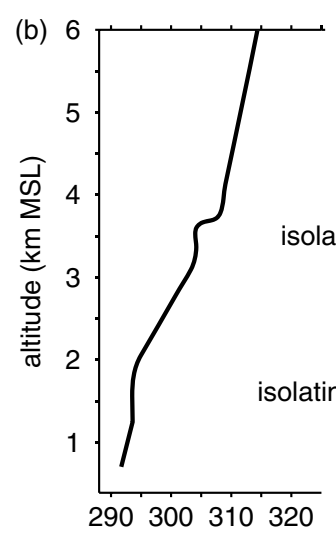

$\downarrow$

$\downarrow$
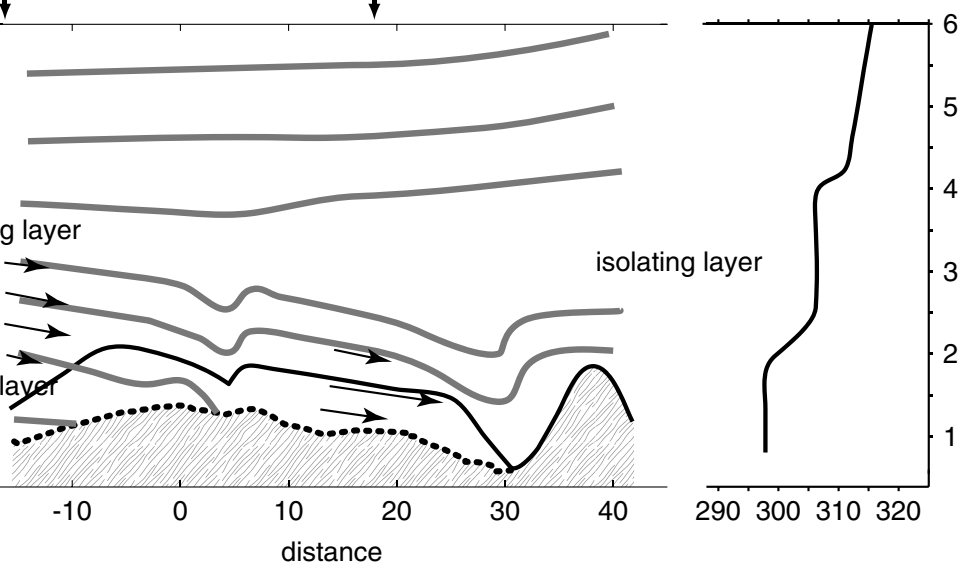

(km)
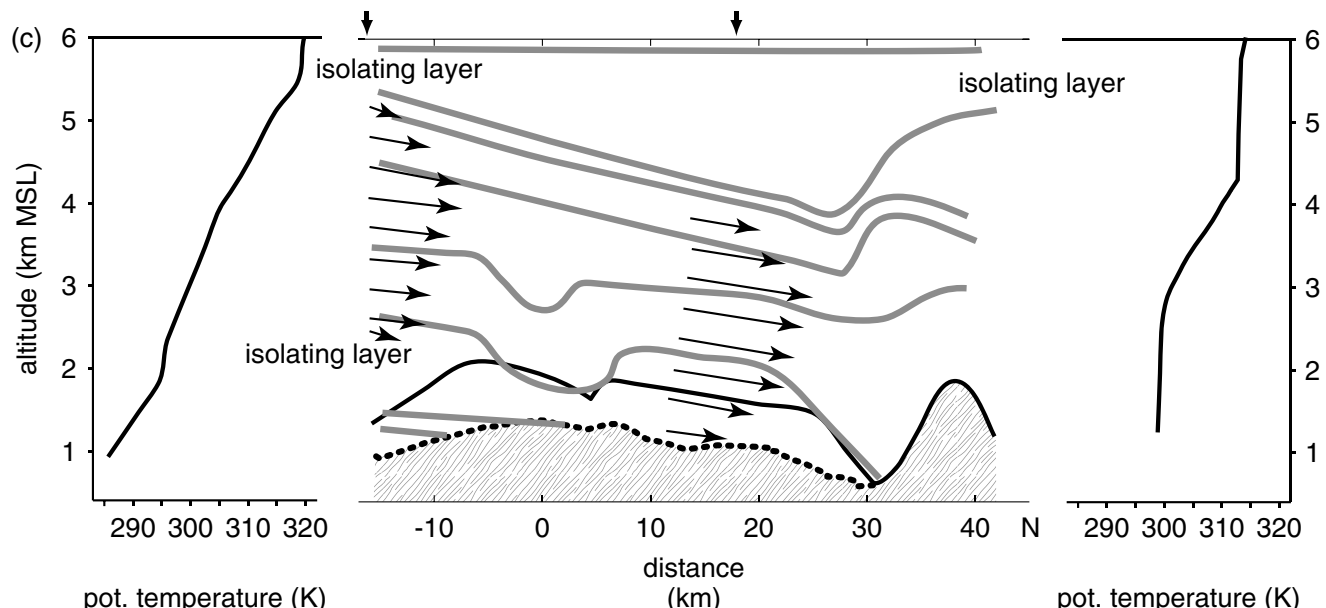

pot. temperature $(\mathrm{K})$

$(\mathrm{km})$

pot. temperature $(\mathrm{K})$

Figure 4. Schematics of three prototypical gap flows. Soundings of potential temperature from upstream and downstream are shown to the left and right, respectively. The approximate locations of these soundings are indicated with arrows above their respective cross-sections. Topography in the sections is shown shaded, bounded by a dashed line at the valley floor. The solid bold line above the valley floor shows the average altitude across the gap 'felt' by the flow. Isentropes (solid grey) are at $2 \mathrm{~K}$ intervals and arrows indicate along-valley speeds upstream and downstream of the gap. (a) shows shallow gap flow behaving with classical single-layer hydraulics of a neutrally stratified layer capped by a very stable layer, and a blocked layer below upstream; (b) shallow, stably stratified gap flow with Wood's (1968) self-similar solution upstream turning into a single-layer flow downstream through turbulent mixing, especially in hydraulic jump(s); (c) deep, stably stratified gap flow both upstream and downstream. From Armi and Mayr (2007).

2007) with an interfacial wave of speed $\sim \sqrt{g^{\prime} h}$ (relative to a possible ambient flow), $h$ being an average depth of the layer between the potential temperature step at the top of the flowing gap layer and the bottom of the upstream topography. In the case of the Wipp Valley with typical values of $\Delta \theta=5 \mathrm{~K}$ and depth $h=2500 \mathrm{~m}$, it takes less than three hours to reach the upwind southern rim of the Alps approximately $200 \mathrm{~km}$ upstream of the gap, 
i.e. the flow reacts relatively quickly and starts flowing towards the gap even upstream of the immediate vicinity of the gap. Interestingly, Zängl's (2002a) numerical simulations with idealized arc-shaped Alps and a gap found a prescribed southerly large-scale flow component below the crest necessary for a longer-lasting gap flow to occur.

Examples of shallow and deep gap flow, as seen by a Doppler lidar downstream of the gap, are shown in Figure 5. The shallow case is a classical single-layer hydraulics flow. Air accelerates past the lidar location and reaches its maximum speed before it reaches the Inn Valley. There is no flow over the crest. The gap flow layer is capped by a strong shear zone topped by nearly stagnant air, shaded light gray in Figure 5(a). Figure 5(b) shows the third prototype, deep föhn flow where the highest speeds descend from above crest level. Note the deepening, nearly stagnant, layer just upstream of the lidar above the gap flow, which allows the gap flow to descend further. Since deep föhn flow 'feels' a different average topography, radial velocities along the downlidar scan direction shown are slower than upstream of the lidar because the gap flow jet is closer to the eastern edge of the valley (not shown), where it reaches its maximum speed.

\subsection{Role of small-scale topography}

While the schematics of Figure 4 show the effects of a topography averaged across the valley, the small-scale variations of the topography both along and across the valley introduce considerable variations in the gap flow. Gohm and Mayr (2004) exploited the basic hydraulic nature of the gap flow and performed sensitivity studies with a numerical hydraulics model. Figure 6 shows that, for a set of different situations of shallow föhn, the locations of supercritical flow are closely fixed to topographical features, mostly to downslopes and lateral constrictions in the valley. Small-scale topographical variations significantly modify the flow. For example, the flow at the first protruding ridge downstream of the pass on the western side of the valley is not uniformly supercritical but rather split into two supercritical regions. The variations are also present in lidar observations obtained during MAP (Figure 7). The flow at a horizontal section at $1980 \mathrm{~m}$ amsl (Figure 7(b)) shows high speeds over the downslope of that first protruding ridge, followed by an abrupt deceleration and another acceleration. There is a velocity component toward the eastern side of the valley, which was also observed with aircraft in situ measurements. Consequently the flow is not symmetrical across the valley. A vertical section of lidar backscatter intensity across the valley (Figure 7(a)) shows an accumulation of gap flow air on the eastern side, visible both in the most intense reflectivity and top of the layer indicated by crosses. An approximately $20^{\circ}$ change of the valley direction, combined with the asymmetry of the topography a few kilometres upstream of the exit of the Wipp Valley at a junction with a tributary valley, also introduces strong flow asymmetries across the valley, which were observed with the Doppler lidar (not shown) (Flamant et al., 2002; Durran et al., 2003; Weissmann et al., 2004; Mayr et al., 2004; Gohm et al., 2004), and are also seen in the hydraulics simulations (Figure 6(a)).

Reduced surface pressure is an integral measure of the flow aloft. The pressure distribution (Figure 6(b)) averaged over all shallow gap flow events of the MAP SOP closely resembles its equivalent in single-layer hydraulics, namely the distribution of the layer depth averaged over all numerical simulations of shallow gap flow. The acceleration of the flow is reflected in a drop of reduced surface pressure and of the depth of the flowing layer. At a hydraulic jump, the pressure stops falling or even rises. Two jump locations just downwind of $47^{\circ} \mathrm{N}$ and immediately upwind of $47.2^{\circ} \mathrm{N}$ were so persistent that they are also visible in the observed averaged pressure distribution. Simulations with mesoscale numerical models of idealized (Zängl, 2003) and case-study flow configurations (Flamant et al., 2002; Gohm et al., 2004; (a)

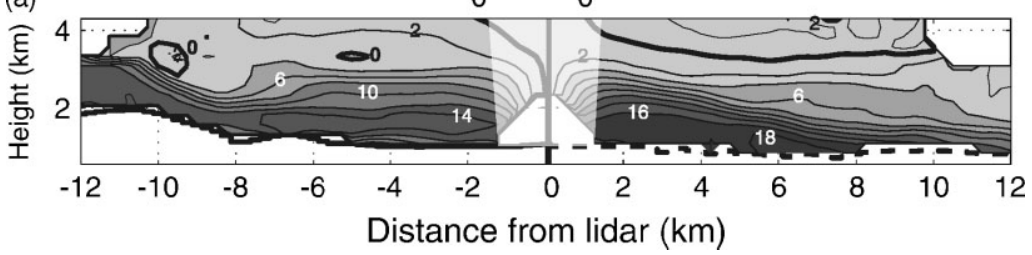

(b)

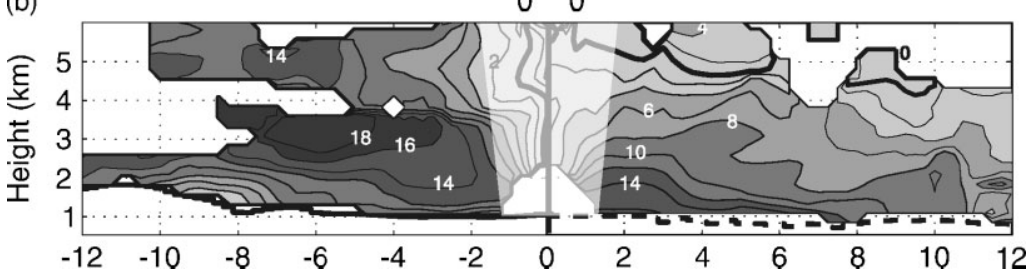

(c)

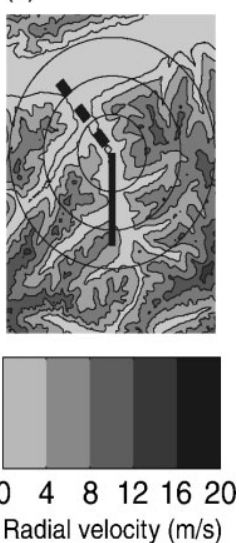

Figure 5. Radial velocity from a Doppler lidar for (a) shallow (11 UTC on 2 October 1999) and (b) deep (11 UTC on 3 October 1999) gap flow in the Wipp Valley along the scans shown in (c) and in Figure 3(b). Gap flow direction is from left to right. Regions with larger differences between radial and horizontal wind component are masked. Adapted from Weissmann et al., 2004. 
(a)
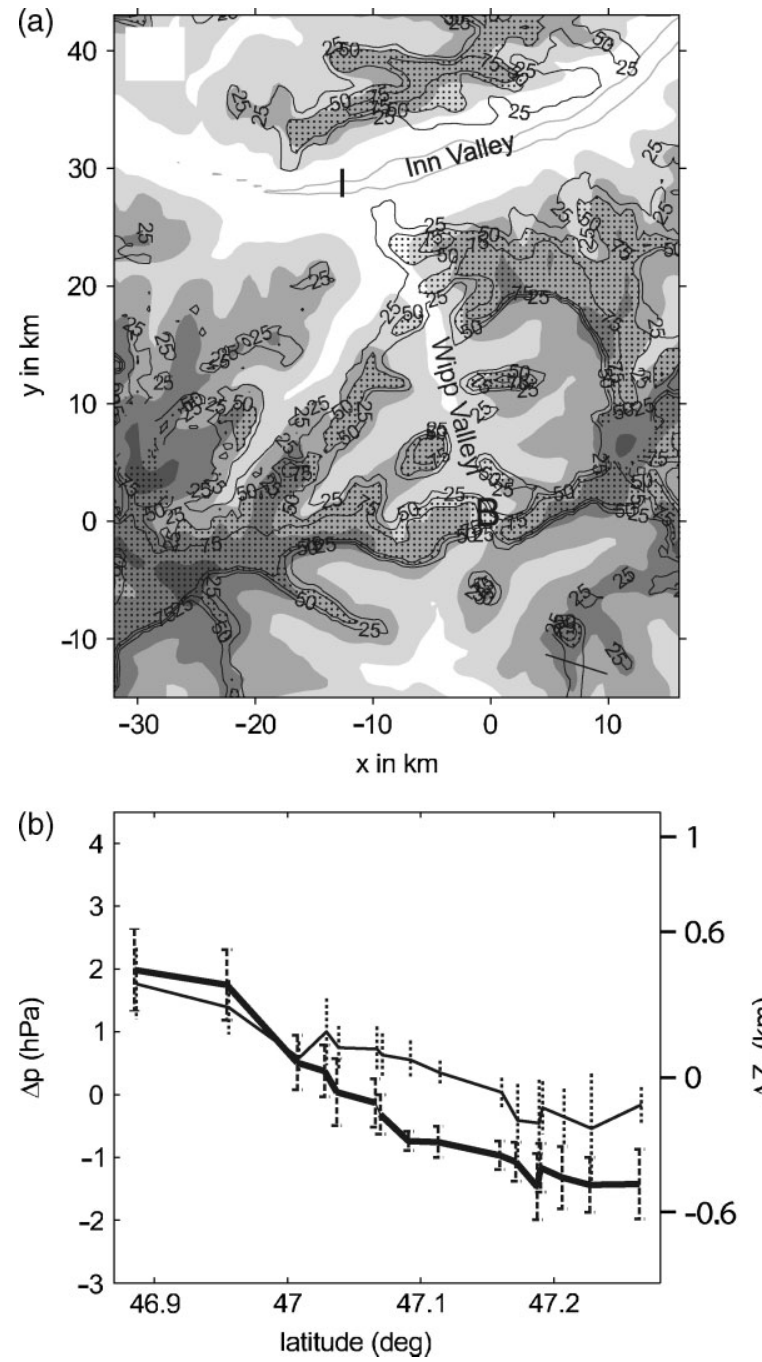

Figure 6. (a) Frequency of supercritical flow at a particular location in numerical simlations of shallow gap flow in the Wipp Valley (large rectangle in Figure 3(a)) with a hydraulic model for ten different intitial conditions. Locations with more than $50 \%$ occurrence are stippled, with \%age contours at 25,50 , and $75 \%$. Underlying topography is shaded in grey. (b) Average pressure difference reduced to a common altitude (bold) from automatic weather stations along the Wipp Valley in shallow gap flows during MAP in autumn 1999 and change of the depth (thin line) of the single layer in the hydraulic model simulation at grid points closest to the location of the weather stations. The vertical bar (dashed for observed pressure; dotted for depth change) extends over 2 standard deviations. Adapted from Gohm and Mayr (2004).

Zängl et al. 2004) provide a complete picture of the modifications caused by small-scale topographical variations.

\subsection{Dynamics of gap flow descent}

An asymmetric gap flow is a special case of a föhn through an incision in a mountain range. As such it shares the question that has puzzled föhn researchers from the beginning and even became the title of an early article (Ficker, 1931): Why does föhn descend to the ground on the downstream side when the air is stably stratified? In model simulations (e.g. Zängl, 2003; Gaberšek and Durran, 2006), a favourable pressure gradient for further downslope propagation of the gap (a)

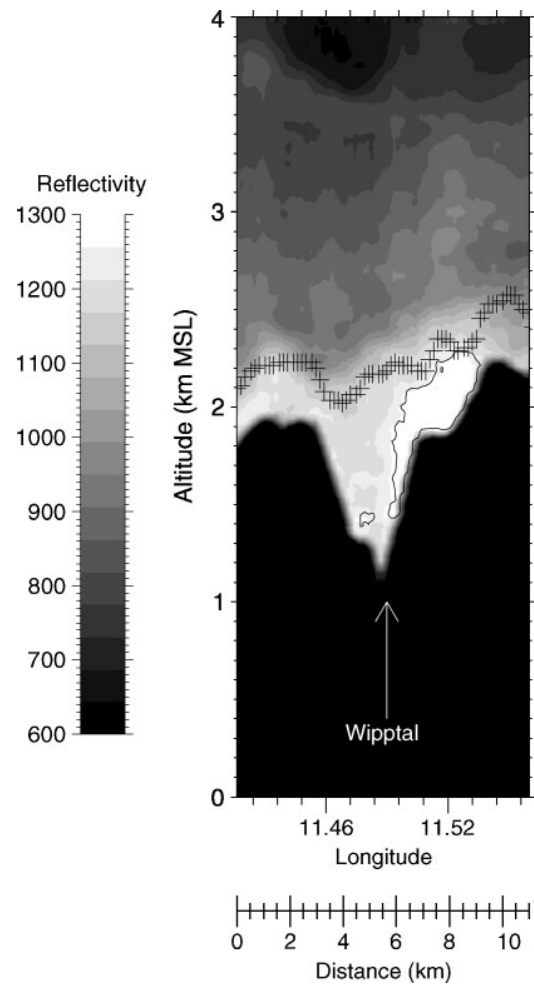

(b)

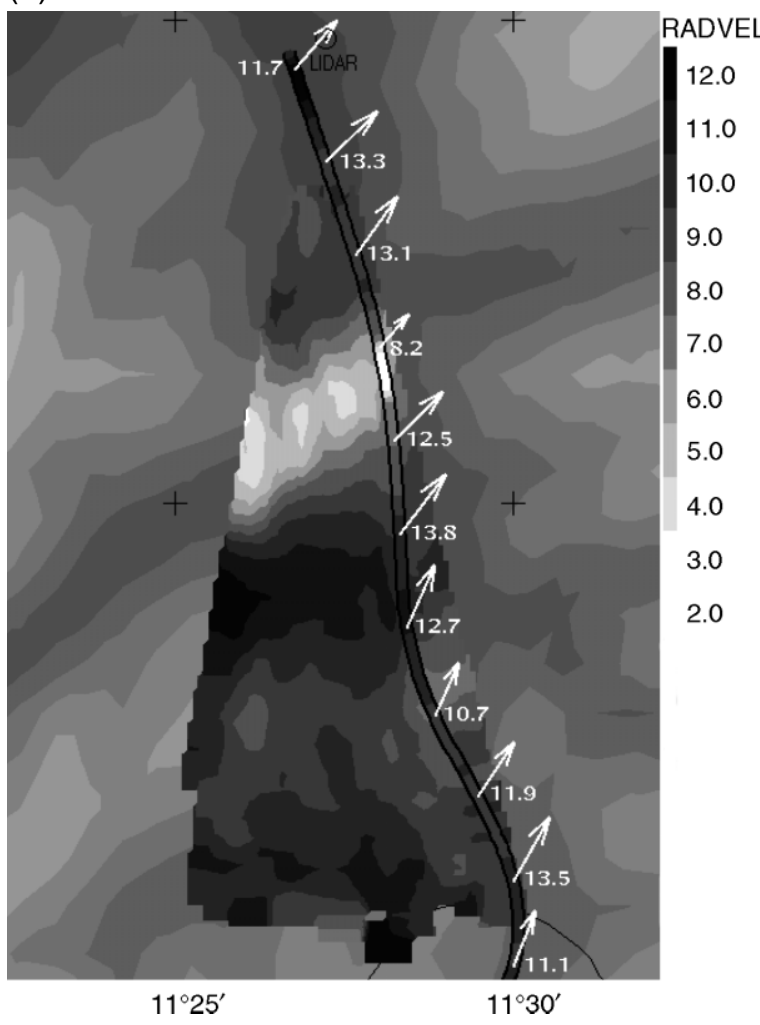

Figure 7. Flow variations caused by small-scale topographical features. (a) Reflectivity from airborne lidar measurements (arbitrary units) across the valley. The top of the gap flow layer is marked by crosses (adapted from Flamant et al., 2002). (b) Radial velocity interpolated to a constant altitude (i.e. not a stream surface) of $1980 \mathrm{~m}$ amsl along the valley (adapted from Durran et al., 2003). The line shows radial velocity and the vectors the horizontal wind measured by the P3 research aircraft. (a) and (b) are marked in Figure 3(b) as the cross-valley line and the small rectangle, respectively. 
flow can be produced by gravity waves. Gravity waves are not needed to interpret the observations of gap flow descent in MAP. Buoyancy forces as used in hydraulics are the key mechanism behind the descent.

In a stably stratified atmosphere, air will descend if its potential temperature is lower than that of the air into which it descends. There are several ways how a dome of potentially cooler air is created on the upstream side, which are discussed in Section 3.6. In such a situation, an isentrope is at a lower altitude on the downstream side and air particles will descend. Baines (2001, 2005) showed theoretically and in the laboratory that if the downstream environment is stably stratified, (negative) buoyancy and frictional forces are approximately balanced for relatively gentle $\left(\leq 20^{\circ}\right)$ slopes. The downflow is approximately mixed with a sharp upper interface, resembling a gravity current on a horizontal surface. Small-scale instabilities at its upper boundary entrain small amounts of downstream environmental air into it. However, detrainment dominates, in which mixed air, which is less dense than the downflow, leaves the downflow to find its own level in the environment. This results in a sharp upper boundary and a continuous loss of air from the downflow. As the downflow reaches the level of neutral buoyancy, the downflow separates from the slope. In the Wipp Valley and most likely other gap flow regions, this location is often at the top of a very stable cold pool, which forms through nocturnal radiative cooling. Slopes downstream of gaps generally fall into the 'gentle' category, e.g. the terrain between the bottom of the middle gap of the Wipp Valley drops by approximately $1700 \mathrm{~m}$ over $30 \mathrm{~km}$, yielding an average slope of $3^{\circ}$. The underlying topography, however, has steeper slopes. The two key features, (nearly) mixed downflow layer and sharp upper boundary are indeed observed in gap flows (cf. Figure 4).

The detrainment on top of the gap flow layer forms a wedge of nearly stagnant and neutrally stratified air, which effectively isolates it from the flow further aloft. This wedge can be seen in Figure 4, and especially in Figure 4(b). So far no atmospheric measurements detailed enough are available to identify its formation mechanisms. While the atmospheric numerical modelling community has proposed larger- (gap-) scale gravity wave breaking as the cause (e.g. Clark and Peltier, 1977; Clark and Peltier, 1984; Peltier and Clark, 1979), Baines's $(2001,2005)$ laboratory results and measurements of an oceanic sill flow (Farmer and Armi, 1999) found detrainment through small-scale shear instabilities to be responsible and pointed out problems with the numeric simulations (initial and lower boundary conditions, and turbulence parametrization: Cummins, 2000; Farmer and Armi, 2001; Afanasyev and Peltier, 2001a,b; Armi and Farmer, 2002).

Figure 8 is an example of flow separation where the eastern edge of the Wipp Valley merges with the Inn Valley. Upstream of the last mountain before the Inn Valley (the Patscherkofel 'PAK' in Figure 8), the flow is subcritical, accelerates, thins and becomes supercritical, and shoots down towards the Inn Valley floor. Approximately $3 \mathrm{~km}$ downstream of the Patscherkofel and $700 \mathrm{~m}$ below it, the flow separates from the surface as it reaches its level of neutral buoyancy and rebounds as a hydraulic jump, where the air is mixed. The air below the separation point has a potential temperature that is $1-2 \mathrm{~K}$ cooler than the gap flow air (cf. Gohm and Mayr, 2004).

Occasionally föhn and gap flows can erode underlying cold pools. The Wipp Valley was not instrumented to study this process. It was one key question studied in another target area of MAP, the Rhine Valley. Results are summarized in Drobinski et al. (2007).

\subsection{Climatology}

How frequently the necessary conditions for gap flow occur - different air masses on both sides of the barrier and/or flow across the crest - depends on the regional setting. Again, the most detailed study available is for the Wipp Valley. There, 'upstream' means the southern side of the Alps, which is warmer on climatological average. Nevertheless, gap flow is frequent and happens for $20 \%$ of the whole year (Föst, 2006). Seasonal differences are pronounced, however (Figure 9). Between June and August the polar frontal zone is too far north to regularly bring cold air to the south of the Alps or cause south(westerly) flow impinging on the Alps ahead of a trough. From December to February, at the height of the cold season, the lowest part of the atmosphere becomes so stable as to often hamper the breakthrough of gap flow to the valley surface. That leaves the transitional months of March/April and September to November to form the two gap flow maxima through a provision of air mass differences and/or flow across the crest and more solar insolation. Nocturnal cooling with accumulation of draining cold air means that the weather station at Innsbruck, a location in the Inn Valley about $400 \mathrm{~m}$ below the one in the Wipp Valley, is frequently below the level of neutral buoyancy of the gap flows. Gap flow frequency at Innsbruck drops by three quarters to only $5 \%$ ! The diurnal cycle is also far more pronounced than at the higher location. Gap flow events generally start around noon and peak in the afternoon when solar insolation has modified the local air mass sufficiently to bring it to the level of neutral buoyancy. The diurnal frequency rises from a nocturnal minimum of $1 \%$ to an afternoon maximum of $14 \%$ compared to minor variations between $20 \%$ and $25 \%$ in the Wipp Valley.

Since gap flows through passes are föhn winds in the WMO (1992) sense, i.e. they descend and are warm and (relatively) dry, the gap flow climatology of the Wipp Valley is also a föhn climatology. The ratio between shallow and deep gap/föhn flows in the lower Wipp Valley is slightly skewed towards deep flows: $40 \%$ of the gap flow duration occurs without a significant crossbarrier wind component at a nearby crest station (Föst 2006, personal communication). 


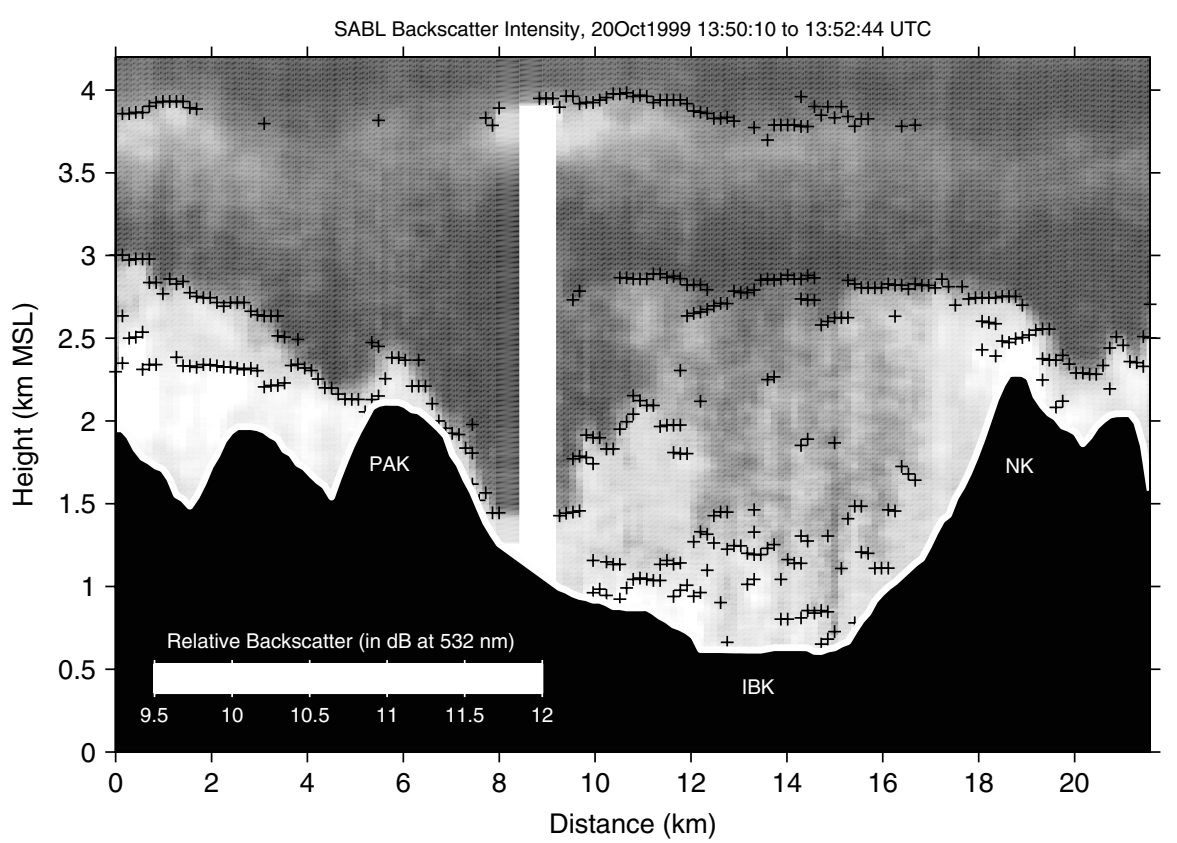

Figure 8. Cross-section along the valley-parallel line in Figure 3(b) of backscatter intensity from aerosol lidar on board the NCAR Electra aircraft on 20 October 1999. The flow separates from the surface near the $9 \mathrm{~km}$ distance marker in a hydraulic jump. Crosses mark the top of aerosol layers, which become mixed after the hydraulic jump. The white vertical strip indicates missing data. The flow is from left to right. PAK is Patscherkofel mountain, IBK is Innsbruck and NK is the northern mountain range (see Figure 3(b)). From Gohm and Mayr (2004).

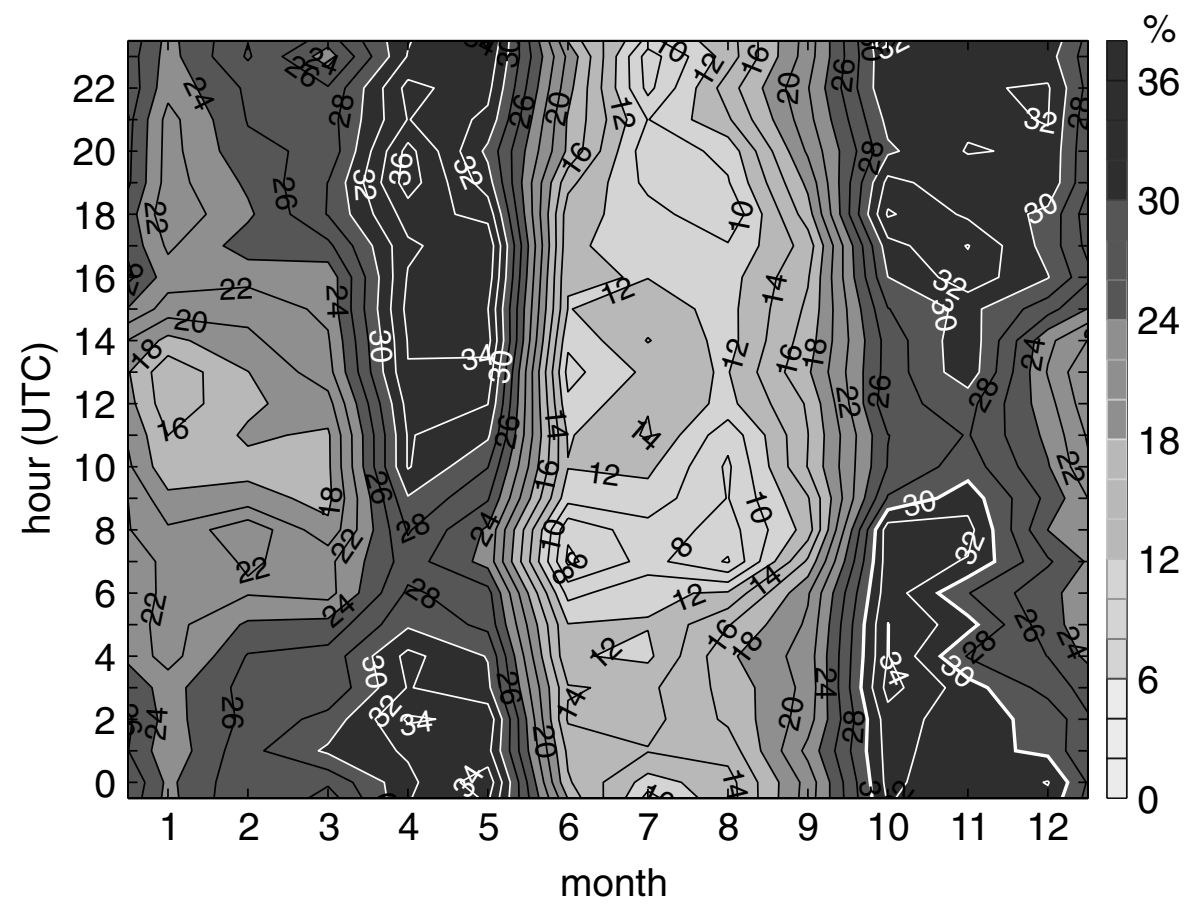

Figure 9. Diurnal and seasonal variation of the frequency of gap flow (shallow and deep) in the lower Wipp Valley. Contours are at $2 \%$ intervals of total time, with grey shading changing every 6\%. Adapted from Föst (2006).

\subsection{Forecasting}

As we have seen in Section 3.5, gap flows may frequently influence the weather - albeit on a local scale making the phenomenon ideally suited for a subjective forecast from an experienced bench forecaster. Current mesh widths of several kilometres (operational limited-area models) and dozens of kilometres (global NWP models) resolve only flows through large gaps, e.g. the Strait of Gibraltar. Statistical post-processing might, however, be used for successful gap flow forecasts.

A bench forecaster has to identify the key ingredients for gap flows:

- different air mass 'reservoirs' on both sides of the gap reaching to an altitude above the bottom of the gap, 
- possibility that the upstream air mass will descend and replace the downstream air mass, and

- flow across the crest in the case of deep gap flow.

Different scenarios can lead to the existence of different air masses on the two sides of the gap:

- Adiabatically through differential horizontal or vertical advection; a larger-scale low further downstream of a gap will ageostrophically drain air towards it. Compensating subsidence will then warm the air downstream of the gap.

- Diabatically through differential air mass modification; in the cold season anticyclones that form over continental land masses create colder air over land than over the surrounding ocean, which in general has warmer surface temperatures. A coastal barrier will therefore have frequent gap flow events. Examples are the mountains at the coast on the eastern side of the Adriatic Sea (bora) and the mountain range separating the Pacific from the interior of North America.

- A combination of radiative forcing and associated surface heat fluxes; low- and mid-level clouds might be present at the upstream side already as a consequence of the air mass or of lifting as the air flows towards the crest and reaches the lifting condensation level. The resulting stratiform cloud layer reduces the absolute value of the net radiation balance at the ground on the upstream side. Subsidence on the downstream side, on the other hand, reduces or eliminates low- and midlevel clouds. In the daytime, air on the downstream side warms to a higher potential temperature. At nighttime the radiative cooling is stronger on the downstream side.

When identifying these processes the forecaster has to be keenly aware of the difference between the actual relief and the model topography.

A frequent forecasting issue is whether a gap flow can penetrate a pool of pre-existing cold air on the downstream side. If the cold pool cannot drain because it is blocked by topography (e.g. in a basin) or by an opposing larger-scale pressure gradient (Zängl, 2005) and sensible heat flux from the surface due to solar insolation warms the pool insufficiently, penetration rarely occurs since turbulence acts to sharpen the density step across the interface between the cold pool and the downslope flow (Lee et al., 1989; Petkovšek, 1992). When the depth of the cold pool is comparable to the size of the turbulent eddies gap flow may penetrate.

The easiest situation to be identified by the forecaster is a deep flow across the crest as it is usually well represented in NWP output. An alternative to the subjective forecast is statistical post-processing of direct model output, which becomes feasible if at least the barrier through which the gap cuts is somehow represented in the model (despite shape and height differences from the real topography). A statistic is required of gap flow occurrence against which the post-processing algorithm

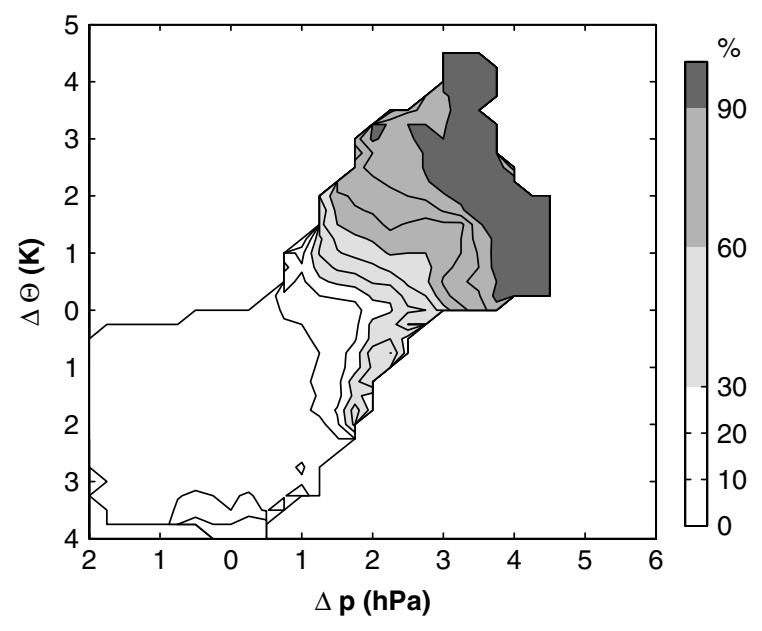

Figure 10. Probability of gap flow occurrence in the lower Wipp Valley from a 3-day forecast of the ECMWF T511 global model as a function of reduced pressure difference, $\Delta p$, between the grid points immediately upstream and downstream of the model Alpine crest, and of the difference in potential temperature, $\Delta \theta$, along a terrain-following model level approximately $300 \mathrm{~m}$ above ground between the grid points at the crest and the one immediately downstream. Adapted from Drechsel and Mayr (2007). The contour interval is $10 \%$.

can be calibrated. The post-processing might be classical model output statistics pioneered by Glahn and Lowry (1972) or a simple, physically based algorithm like the one developed by Drechsel and Mayr (2007), which they applied to the Wipp Valley. Different air masses on the two sides of a barrier manifest themselves in reduced surface pressure. Different air masses and/or flow over the crest also cause the isentropes to descend across the model-resolved barrier and potential temperature to increase along a terrain-following model level, respectively. The combined distribution function, shown for a 72-hour forecast with the ECMWF T511 global model in Figure 10, allows a probabilistic instead of a categorical forecast of gap flow.

A direct forecast of gap flow by an NWP model will depend on its ability to properly resolve the terrain and to correctly represent the processes leading to different reservoirs and the turbulent mixing processes at the top of the gap flow layer, in hydraulic jumps, and at the surface of the complex topography. For a gap the size of the Brenner Pass, operational NWP cannot yet meet these conditions. Research models are partially successful, as is discussed further in Section 4.2.

\section{Discussion}

Since the MAP field campaign, an ever-increasing research effort has gone into studying gap flows and their effects on local weather and climate. Topographical settings different from the Wipp Valley allow for additional phenomena to occur. When gap flow discharges over the ocean, a gap jet may extend over dozens of kilometres and merge with jets emanating from adjacent gaps in a coastal barrier (Gohm and Mayr, 2005, for the bora on the Adriatic Sea) or combine with a barrier jet (Loescher 
et al., 2006, along the Northern American Pacific coast). When the terrain downstream of a gap does not run perpendicular to the crest, shallow flow through the gap forms a highly turbulent shear zone with the overlying deep flow across the crest (Bond et al., 2006, for the Taku wind in Alaska), which poses an aviation hazard also found in the vicinity of Hong Kong International airport. Advection of a different air mass through the gap can locally modify the level of pollutants, e.g. in the Mexico City basin (Doran and Zhong, 2000) or at the California coast (Neimann et al., 2006). In general, the descent associated with gap flow will locally decrease precipitation (Neimann et al., 2006), but may enhance it under particular topographical and air mass conditions on the downwind side (Colle and Mass, 1998; Sharp and Mass, 2004). Finally, gap flow climatologies could be compiled for several locations along the Pacific coast (Sharp and Mass, 2004; Neimann et al., 2006), in addition to older climatologies for the Adriatic coast (e.g. Bajić, 1989).

Progress in the understanding of gap flows initiated by the GAP project of MAP has been built on the application of hydraulic theory (cf. Section 3.2) and the successful intertwining of the analysis of a dense 4D observational dataset with high-resolution numerical simulations. Based on the experience from MAP, recommendations for future gap flow experiments and numerical simulations can be made.

\subsection{Observational methods}

Only some parts of the ideal of continuous volume and/or line measurements of the mass and wind field can be realized with today's measurement equipment. The synergies between several measurement platforms and remote sensing and in situ methods have to be used. Crucial is a frequent (less than 3 hours) sampling of the vertical structure of temperature and wind of both the upstream and downstream reservoir. The current mainstay for temperature and humidity is still the radiosonde. An accurate (better than $0.5 \mathrm{~K}$ ) remote sensor for quasi-continuous temperature measurements with a vertical resolution of better than $30 \mathrm{~m}$ up to mid-tropospheric levels is sorely needed but (to our knowledge) is not available. A radio-acoustic sounding system added on to wind profilers reaches typically to $1 \mathrm{~km}$, which is not high enough. Wind profilers are remote-sensing alternatives to radiosondes with higher temporal resolution (30 minutes or shorter), but experience problems of low signal-to-noise ratios especially in dry environments. A scanning Doppler lidar allows radial velocity measurements unmarred by ground clutter over a large volume up to $5-10 \mathrm{~km}$ away from the instrument, provided there are enough backscatterers. With the addition of a second Doppler lidar and the application of the continuity equation, the 3D wind field can be retrieved with methods similar to the ones long in use for dual-Doppler weather radar set-ups (e.g. Chong and Bousquet, 2001). Due to the difference of aerosol content within the gap flow layer and the adjacent air, scanning aerosol lidars are ideally suited to track depth changes of gap flow, which indicate its subcritical or supercritical state. Regions of subcritical and supercritical flow conditions and hydraulic jumps can also be deduced from pressure measurements with lines of automated weather stations, provided the stations are carefully intercalibrated, dynamic pressure is eliminated through a static pressure port (Nishiyama and Bedard, 1991), and a sophisticated reduction to a common altitude is performed (Mayr et al., 2002). An alternative is a mobile platform (Mayr et al., 2002) offering higher spatial resolution at the expense of temporal resolution.

Aircraft serve as platforms for remote sensors, dropsondes and in situ measurements, but the latter are expensive and limited to daylight and visual meteorological conditions. Depending on the depth and horizontal extent of the gap flow, a complete in situ sampling in a period during which the flow remains quasi-stationary might be difficult to achieve (Mayr et al., 2004). Dropsondes provide more instantaneous vertical cross-sections of temperature, wind and moisture fields (e.g. Armi and Mayr, 2007), if permission to drop can be obtained and the frequently narrow gap flows are accurately targeted. Aircrafts are particularly useful for gap flow studies when equipped with remote-sensing instrumentation so that complete sections perpendicular and parallel to the gap can be measured in a short period of time. The same measurement principles as for their ground-based counterparts can be exploited: aerosol backscatter (Flamant et al., 2002; Gohm and Mayr, 2005, 2005) for the depth of the gap flow layer, Doppler processing with scanning or use of a pseudo-dual-Doppler technique for 3D wind (Weissmann et al., 2005), and amount of water or ozone as air mass tracer from a differential absorption lidar. The application of lidar is limited to regions with broken or no cloud cover. Wind in cloudy regions might however be measured with an airborne Doppler radar. Typically the upstream cloud cover is stratiform and non-precipitating, i.e. a cloud radar with a wavelength of $1 \mathrm{~cm}$ or less is needed. A weather radar with longer wavelengths obtains wind only in precipitation regions.

Two aspects of gap flow, the formation of the wedge of nearly neutral and stagnant air on top of the gap flow layer and the separation of gap flow from the ground, could not be studied with the MAP instrumentational set-up. A combination of carefully positioned ground-based and airborne remote sensors with the capability of measuring wind and temperature with a spatial resolution $\mathrm{O}(10 \mathrm{~m})$ will be needed for a successful observation.

\subsection{Numerical simulations}

Simulating gap flows in realistic settings challenges current models. The essential features of a gap flow that a numerical model should capture are its depth, the strength of the interface on its top, turbulent detrainment with the formation of the nearly neutral and stagnant wedge on top of the gap flow layer downstream, and the locations where flow separation and hydraulic jumps occur. Getting the initial conditions right is the first major challenge. 
The horizontal resolution must be high enough to resolve the gap. Since topography must be smoothed to at least $2 \Delta x$ so that no disturbances are excited that the numerical diffusion scheme cannot remove, horizontal mesh sizes of a few hundred metres might be needed. Simulations for the Wipp Valley (Zängl et al., 2004; Gohm et al., 2004) used $267 \mathrm{~m}$ as the finest meshes. Without a properly resolved gap, the mass flux through it (Gohm et al., 2004) and the location of flow separation points (Ross and Vosper, 2003) and hydraulic jumps will be inaccurate. Proper representation of the air masses on both sides of the gap is difficult. Currently most mesoscale models obtain the initial state through an interpolation of analyses produced by data assimilation schemes of global models, which in general do not resolve the gap scale and often have to discard observations in complex topography where the differences between model and real topography are large. Evolving the correct initial state through a prolonged spin-up of the mesoscale model often fails since e.g. the evolution of local valley wind systems or cold pools strongly depend on the air mass properties and on conditions of the surface (soil moisture and temperature, vegetation, land use; Chow et al., 2006), which are insufficiently known. For case-studies, fields can be corrected manually (Zängl et al., 2004, appendix). For operational mesoscale forecast models, both a better assimilation algorithm than the commonly used nudging and adequate measurements of soil moisture and temperature are needed. Without them, air masses in the model on both sides of the gap might be similar and no shallow gap flow evolves. If a gap flow does evolve, the level of neutral buoyancy and thus the penetration depth on the downstream side can be poorly represented. A first improvement was achieved with an optimum interpolation scheme (Jaubert et al., 2005, and references therein) for föhn simulations in the Rhine Valley.

The second challenge for the numerical simulation lies in the numerics of the models. Terrain-following vertical coordinate systems introduce numerical artifacts, especially in advective and diffusive processes, since derivatives along the model surface are significantly away from being horizontal. Promising modifications are in the coordinate system itself (Schär et al., 2002), and making the horizontal diffusion truly horizontal, at least for temperature and moisture (Zängl, 2002b). Without a truly horizontal diffusion, a cold pool in a valley cannot be maintained since mixing along the sloping coordinate surface takes place; descent of the gap flow and flow separation cannot be properly simulated. Since detrainment at the top of the gap flow layer is a crucial process (cf. Section 3), the small-scale turbulent processes have to be properly parametrized. The scheme of Mellor and Yamada (1982), which (or one of its modifications) is widely used in mesoscale models, produces too little detrainment. The alternative, large-eddy parametrizations (e.g. Deardorff, 1980), are not perfectly suitable either, since horizontal (several hundred metres) and vertical (dozens of metres) grid meshes are not of similar magnitude. Thus it is not surprising that it has only recently been noticed that flow separation and breakthrough of gap flows to lower terrain strongly depend on the turbulence parameterization and which values of the exchange coefficients are used (Gohm 2005, personal communication). Failure of the turbulence scheme to create the correct stratification might even affect the upstream part of the gap. A thorough comparison of model simulations with observations (Gohm et al., 2004) identified an incorrect upstream profile with a too shallow gap flow layer immediately upstream of the Wipp Valley gap as the largest discrepancy between observations and model, despite a correct profile further upstream. Incorrectly represented physics leading to the formation of the inversion at the top of the gap flow layer was suspected. This led to an incorrect mass flux and descent on the downstream side. Results from the boundary layer subproject of MAP (Rotach and Zardi, 2007) point to ways of improving the turbulence parametrization over complex terrain.

\section{Conclusions}

Project P4 of the Mesoscale Alpine Programme and later field campaigns of smaller scope have focused on the flow through indentations in mountain ranges. Such indentations range from solely lateral constrictions of the terrain (level gap) to a combination of lateral and vertical constrictions as found in a pass. The flow configuration studied in detail was one of a deeper, relatively slowmoving upstream layer that accelerates and thins through the gap and downstream of it. One conceptual way to describe the flow situation is that of two reservoirs of differing depth far upstream and downstream of the gap. These reservoirs can be formed by different air masses, with a dome of air of lower potential temperature upstream, and/or a flow towards the gap caused by a mesoscale or even synoptic-scale pressure gradient force, which piles air up on the upstream side of the gap. At least for the gap in the Alpine Wipp Valley and gaps in the Dinaric Alps (but most likely also for other gaps), the hydraulic (or reduced-gravity shallowwater) framework is the simplest way to describe the essential features of these strongly nonlinear flows. The simplest prototype of gap flow identified was one of a single (i.e. nearly mixed) flowing layer that transits from a subcritical to a supercritical state at the region of the most pronounced topographical constriction, i.e. the gap. The gap then controls the volume flux through it. Since typically the depth of the upstream reservoir is preset by the upstream air mass or flow towards the obstacle, only one particular value of volume flux through the gap is possible. Past the gap, the flow accelerates further and its depth and the (reduced) pressure at the surface keep decreasing until it adjusts to the presence of the downstream reservoir in a hydraulic jump, where some of the kinetic energy is turbulently removed and some transformed into potential energy as the isentropes rise again and consequently the pressure increases. The single-layer prototype was found for shallow gap flow 
where there is (almost) no flow across the crest. The second and third prototypes are for a continuously and stably stratified upstream reservoir. For a constriction, an analytical hydraulic solution (Wood, 1968) exists with a sort of parabolic velocity profile and a bounding, nearly neutrally stratified layer at the top and bottom of the gap flow layer upstream. Depending on the depth of the flow and the gap, and the strength of turbulent mixing in the boundary layer and hydraulic jump(s), the stratification either remains stable downstream of the gap (most likely with deep föhn) or is mixed into a single neutral layer.

The topography-related descent of the air makes gap flows a special case of föhn (cf. Drobinski et al., 2007), which was intuitively realized through the concept of shallow and deep föhn (Kanitscheider, 1932; Vergeiner, 1983, p.119) and formally understood in MAP. Smallscale variations of the topography strongly influence and modify gap flow by causing additional hydraulic jumps, launching gravity waves or leading to horizontal or vertical flow separation or flow re-attachment (cf. Gohm and Mayr, 2005).

The GAP project of the Mesoscale Alpine Programme has gathered the most comprehensive observational gap flow dataset to date. The data are available to the research community at http://www.map.meteoswiss. ch. There is still much room for continued exploitation.

\section{Acknowledgements}

We are indebted to all who gathered the measurements in MAP and all who have worked towards a better understanding of gap flows. Thanks also go to the numerous national and international institutions which funded the research. We particularly thank the reviewers and the editor for their constructive evaluation of the manuscript. The first author was partly supported by the Austrian Science Foundation FWF P15077-N10 and P18940-N10.

\section{References}

Afanasyev YD, Peltier WR. 2001a. On breaking internal waves over the sill in Knight Inlet. Proc. R. Soc. London A 457: 2799-2825.

Afanasyev YD, Peltier WR. 2001b. Reply to comment on the paper 'On breaking internal waves over the sill in Knight Inlet'. Proc. R. Soc. London A 457: 2831-2834.

American Meteorological Society. 1999. Glossary of Meteorology. Amer. Meteorol. Soc.: Boston, USA.

Arakawa S. 1969. Climatological and dynamical studies on the local strong winds, mainly in Hokkaidō, Japan. Geophys. Mag. 34: $359-425$.

Armi L, Farmer D. 2002. Stratified flow over topography: bifurcation fronts and transition to the uncontrolled state. Proc. R. Soc. London A 458: 513-538.

Armi L, Mayr GJ. 2007. Continuously stratified flow across an Alpine crest with a pass: Shallow and deep föhn. Q. J. R. Meteorol. Soc. 133: 459-477.

Armi L, Williams R. 1993. The hydraulics of a stratified fluid flowing through a contraction. J. Fluid Mech. 251: 355-375.

Baines PG. 2001. Mixing in flows down gentle slopes into stratified environments. J. Fluid Mech. 443: 237-270.

Baines PG. 2005. Mixing regimes for the flow of dense fluid down slopes into stratified environments. J. Fluid Mech. 538: 247-267.

Bajić A. 1989. Severe bora on the northern Adriatic. Part 1: Statistical analysis. Rasprave 24: 1-9.
Bond NA, Dierking CF, Doyle JD. 2006. Research aircraft and wind profiler observations in Gastineau channel during a taku wind event. Weather and Forecasting 21: 489-501.

Cameron DC. 1931. Easterly gales in the Columbia River Gorge during the winter of 1930-1931: Some of their causes and effects. Mon. Weather Rev. 59: 411-413.

Cameron DC, Carpenter AB. 1936. Destructive easterly gales in the Columbia River gorge, December 1935. Mon. Weather Rev. 64: 264-267.

Chong M, Bousquet O. 2001. On the application of MUSCAT to a ground-based dual-Doppler radar system. Meteorol. Atmos. Phys. 78: 133-139.

Chow FK, Weigel AP, Street RL, Rotach MW, Xue M. 2006. Highresolution large-eddy simulations of flow in a steep Alpine valley. Part 1: Methodology, verification, and sensitivity experiments. $J$. Appl. Meteorol. 45: 63-86.

Clark T, Peltier W. 1977. On the evolution and stability of finiteamplitude mountain waves. J. Atmos. Sci. 34: 1715-1730.

Clark T, Peltier W. 1984. Critical level reflection and the resonant growth of nonlinear mountain waves. J. Atmos. Sci. 41: 3122-3134.

Clark T, Peltier W. 1998. Windstorms along the western side of the Washington Cascade mountains. Part I: A high-resolution observational and modeling study of the 12 February 1995 event. Mon. Weather Rev. 126: 28-52.

Clark T, Peltier W. 2000. High-resolution observations and numerical simulations of easterly gap flow through the Strait of Juan de Fuca on 9-10 December 1995. Mon. Weather Rev. 128: 2398-2422.

Colman BR, Dierking CF. 1992. The Taku wind of southeast Alaska: Its identification and prediction. Weather and Forecasting 7: 49-64.

Cummins PF. 2000. Stratified flow over topography: time-dependent comparisons between model solutions and observations. Dyn. Atmos. Oceans 33: 43-72.

Deardorff JW. 1980. Stratocumulus-capped mixed layers derived from a three-dimensional model. Boundary-Layer Meteorol. 18: 495-527.

Doran JC, Zhong S. 2000. Thermally driven gap winds into the Mexico City basin. J. Appl. Meteorol. 39: 1330-1340.

Dorman CE, Beardsley RC, Limeburner R. 1995. Winds in the Strait of Gibraltar. Q. J. R. Meteorol. Soc. 121: 1903-1921.

Drechsel S, Mayr GJ. 2007. Objective forecasting of föhn for a subgridscale Alpine valley. Weather and Forecasting. In press.

Drobinski P, Steinacker R, Richner H, Baumann-Stanzer K, Beffrey G, Benech B, Berger H, Chimani B, Dabas A, Dürr B, Flamant C, Frioud M, Furger M, Gröhn I, Gubser S, Gutermann T, Häberli C, Häller-Scharnhorst E, Jaubert G, Lothon M, Mitev V, Pechinger U, Piringer M, Ratheiser M, Ruffieux D, Seiz G, Spatzierer M, Tschannet S, Vogt S, Werner R, Zängl G. 2007. Föhn in the Rhine Valley during MAP: A review of its multiscale dynamics in a complex valley geometry. Q. J. R. Meteorol. Soc. 133: 897-916.

Durran D, Klemp J. 1987. Another look at downslope winds. Part II: Nonlinear amplification beneath wave-overturning layers. J. Atmos. Sci. 44: 3402-3412.

Durran DR, Maric T, Banta RM, Darby LS, Hardesty RM. 2003. A comparison of ground-based Doppler lidar and airborne in situ wind observations above complex terrain. Q. J. R. Meteorol. Soc. 129: 693-713.

Farmer DM, Armi L. 1999. Stratified flow over topography: the role of small-scale entrainment and mixing in flow establishment. Proc. R. Soc. London A 455: 3221-3258.

Farmer DM, Armi L. 2001. Stratified flow over topography: models versus observations. Proc. R. Soc. London A 457: 2827-2830.

Ficker H. 1931. Warum steigt der Föhn in die Täler herab? Meteorol. Zeitschrift 48: 227-229.

Flamant C, Dobrinski P, Nance L, Banta R, Darby L, Dusek J, Hardesty M, Pelon J, Richard E. 2002. Gap flow in an Alpine valley during a shallow south föhn event: Observations, numerical simulations and hydraulic analogue. Q. J. R. Meteorol. Soc. 128: 1173-1210.

Föst F. 2006. 'Eine objektive Föhnklimatologie für das Wipp- und Inntal'. Master's diploma thesis: Freie Universität Berlin and University of Innsbruck. http://meteo.uibk.ac.at/theses/diplomatheses.

Gaberšek S, Durran DR. 2004. Gap flows through idealized topography. Part I: Forcing by large-scale winds in the non-rotating limit. $J$. Atmos. Sci. 61: 2846-2862.

Gaberšek S, Durran DR. 2006. Gap flows through idealized topography. Part II: Effects of rotation and surface friction. J. Atmos. Sci. 63: 2720-2739.

Glahn HR, Lowry DA. 1972. The use of model output statistics (MOS) in objective weather forecasting. J. Appl. Meteorol. 11: 1203-1211.

Gohm A, Mayr GJ. 2004. Hydraulic aspects of föhn winds in an Alpine valley. Q. J. R. Meteorol. Soc. 130: 449-480. 
Gohm A, Mayr GJ. 2005. Numerical and observational case-study of a deep Adriatic bora. Q. J. R. Meteorol. Soc. 131: 1363-1392.

Gohm A, Zängl G, Mayr GJ. 2004. South foehn in the Wipp Valley on 24 October 1999 (MAP IOP 10): Verification of high-resolution numerical simulations with observations. Mon. Weather Rev. 132: $78-102$.

Grubišić V, Cardon S. 2002. 'Climatology of the Sierra Nevada mountain-wave clouds'. Pp 392-393 in preprints for 10th AMS Conf. on Mountain Meteorology, June 2002, Park City, UT. American Meteorol. Soc: Boston, USA.

Holmboe J, Klieforth H. 1954. 'Sierra Wave Project Final Report'. Technical report, University of California at Los Angeles, contract No. AF 19(122)-263.

Hurd WE. 1929. Northers of the Gulf of Tehuantepec. Mon. Weather Rev. 57: 192-194.

Jackson PL, Steyn DG. 1994a. Gap winds in a fjord. Part I: Observations and numerical simulation. Mon. Weather Rev. 122: 2645-2665.

Jackson PL, Steyn DG. 1994b. Gap winds in a fjord. Part II: Hydraulic analog. Mon. Weather Rev. 122: 2666-2676.

Jaubert G, Bougeault P, Berger H, Chimani B, Flamant C, Häberli C, Lothon M, Nuret M, Vogt S. 2005. Numerical simulation of mesogamma scale features of föhn at ground level in the Rhine valley. O. J. R. Meteorol. Soc. 131: 1339-1361.

Kanitscheider R. 1932. Beiträge zur Mechanik des Föhns. Beitr. Phys. frei. Atmos. 18: 27-49.

Klemp JB, Lilly DK. 1975. The dynamics of wave-induced downslope winds. J. Atmos. Sci. 32: 320-339.

Lee T, Pielke R, Kessler R, Weaver J. 1989. Influence of cold pools downstream of mountain barriers on downslope winds and flushing. Mon. Weather Rev. 117: 2041-2058.

Loescher KA, Young GS, Colle BA, Winstead NS. 2006. Climatology of barrier jets along the Alaskan coast. Part I: Spatial and temporal distributions. Mon. Weather Rev. 134: 437-453.

Long RR. 1953. Some aspects of the flow of stratified fluids. I: A theoretical investigation. Tellus 5: 42-57.

Long RR. 1954. Some aspects of the flow of stratified fluids. II: Experiments with a two-fluid system. Tellus 6: 97-115.

Long RR. 1955. Some aspects of the flow of stratified fluids. III: Continuous density gradients. Tellus 7: 341-357.

Mayr GJ, Vergeiner J, Gohm A. 2002. An automobile platform for the measurement of föhn and gap flows. J. Atmos. Oceanic Technol. 19: $1545-1556$.

Mayr GJ, Armi L, Arnold S, Banta RM, Darby LS, Durran DR, Flamant C, Gaberšek S, Gohm A, Mayr R, Mobbs S, Nance LB, Vergeiner I, Vergeiner J, Whiteman CD. 2004. Gap flow measurements during the Mesoscale Alpine Programme. Meteorol. Atmos. Phys. 86: 99-119.

Mellor GL, Yamada T. 1982. Development of a turbulence closure model for geophysical fluid problems. Rev. Geophys. Space Phys. 20: $851-875$.

Mobbs S, Vosper S, Sheridan P, Cardoso R, Burton R, Arnold S, Hill M, Horlacher V, Gadian A. 2005. Observations of downslope winds and rotors in the Falkland Islands. Q. J. R. Meteorol. Soc. 131: 329-351.

Neiman PJ, Ralph FM, White AB, Parrish DD, Holloway JS, Bartels DL. 2006. A multiwinter analysis of channeled flow through a prominent gap along the northern California coast during CALJET and PACJET. Mon. Weather Rev. 134: 1815-1841.

Nishiyama RT, Bedard AJJ. 1991. A 'quad-disc' static pressure probe for measurement in adverse atmospheres: With a comparative review of static pressure probe designs. Rev. Sci. Instrum. 62: 2193-2204.

Pan F, Smith RB. 1999. Gap winds and wakes: SAR observations and numerical simulations. J. Atmos. Sci. 56: 905-923.

Peltier W, Clark T. 1979. The evolution and stability of finite-amplitude mountain waves: Part II: Surface wave drag and severe downslope windstorms. J. Atmos. Sci. 36: 1498-1529.

Petkovšek Z. 1992. Turbulent dissipation of cold air lake in a basin. Meteorol. Atmos. Phys. 47: 237-245.

Pettre P. 1982. On the problem of violent valley winds. J. Atmos. Sci. 39: $542-554$

Prandtl L. 1942. Führer durch die Strömungslehre. Friedr. Vieweg \& Sohn: Braunschweig.

Queney P. 1948. The problem of airflow over mountains: A summary of theoretical studies. Bull. Am. Meteorol. Soc. 29: 16-26.

Reed TR. 1931. Gap winds of the Strait of Juan de Fuca. Mon. Weather Rev. 59: 373-376.

Richner H, Baumann-Stanzer K, Benech B, Berger H, Chimani B, Dorninger M, Drobinski P, Furger M, Gubser S, Guternmann T, Häberli C, Häller E, Lothon M, Mitev V, Ruffieux D, Seiz G,
Steinacker R, Tschannett S, Vogt S, Werner R. 2006. Unstationary aspects of föhn in a large valley. Part I: Operational setup, scientific objectives and analysis of the cases during the special observing period of the MAP subprogramme form. Meteorol. Atmos. Phys. 92 $255-284$.

Ross AN, Vosper SB. 2003. Numerical simulations of stably stratified flow through a mountain pass. Q. J. R. Meteorol. Soc. 129: 97-115.

Rotach MW, Zardi D. 2007. On the boundary structure over highly complex terrain: Key findings from MAP. Q. J. R. Meteorol. Soc. 133: $937-948$

Schär C, Smith R. 1993. Shallow-water flow past isolated topography. Part I: Vorticity production and wake formation. J. Atmos. Sci. 50: 1373-1400.

Schär C, Leuenberger D, Fuhrer O, Luethi D, Girard C. 2002. A new terrain-following vertical coordinate formulation for atmospheric prediction models. Mon. Weather Rev. 130: 2459-2480.

Schär C, Sprenger M, Lüthi D, Jiang Q, Smith RB, Benoit R. 2003. Structure and dynamics of an Alpine potential-vorticity banner. $Q$. J. R. Meteorol. Soc. 129: 825-855.

Scorer RS. 1952. Mountain-gap winds: A study of surface wind at Gibraltar. Q. J. R. Meteorol. Soc. 78: 53-61.

Seibert P. 1990. South föhn studies since the ALPEX experiment. Meteorol. Atmos. Phys. 43: 91-103.

Sharp J, Mass CF. 2004. Columbia Gorge gap winds: Their climatological influence and synoptic evolution. Weather and Forecasting 19: 970-992.

Smith RB. 1979. The influence of mountains on the atmosphere. Pp 87-230 of Advances in Geophysics, Saltzman B (ed). Academic Press: New York.

Smith RB. 1980. Linear theory of stratified hydrostatic flow past an isolated mountain. Tellus 32A: 348-364.

Smith RB. 1985. On severe downslope winds. J. Atmos. Sci. 42: 2597-2603.

Sprenger M, Schär C. 2001. Rotational aspects of stratified gap flows and shallow föhn. Q. J. R. Meteorol. Soc. 127: 161-187.

Vergeiner I. 1983. 'Dynamik alpiner Windsysteme'. Technical report, Institut für Meteorologie und Geophysik, Universität Innsbruck, Austria.

Vergeiner J. 2004. 'South föhn studies and a new föhn classification scheme in the Wipp and Inn Valley'. PhD thesis, Institut für Meteorologie und Geophysik, Universität Innsbruck, Austria.

Volkert H, Gutermann T. 2007. Inter-domain cooperation for mesoscale atmospheric laboratories. The Mesoscale Alpine Programme as a rich study case. Q.J.R. Meteorol. Soc. 133: 949-967.

Weissmann MD, Mayr GJ, Banta RM, Gohm A. 2004. Observations of the temporal evolution and spatial structure of the gap flow in the Wipp Valley on 2 and 3 October 1999. Mon. Weather Rev. 132: 2684-2697.

Weissmann MD, Braun F, Gantner L, Mayr GJ, Rahm S, Reitebuch O. 2005. The Alpine mountain-plain circulation: Airborne Doppler lidar measurements and numerical simulations. Mon. Weather Rev. 133: $3095-3109$

World Meteorological Organization. 1992. International meteorological vocabulary. Publication No. 182, 2nd edition. WMO: Geneva.

Wood IR. 1968. Selective withdrawal from a stably stratified fluid. $J$. Fluid Mech. 32: 209-223.

Zängl G. 2002a. Idealized numerical simulations of shallow föhn. $Q$. J. R. Meteorol. Soc. 128: 431-450.

Zängl G. 2002b. An improved method for computing horizontal diffusion in a sigma-coordinate model and its application to simulations over mountainous topography. Mon. Weather Rev. 130: $1423-1432$.

Zängl G. 2002c. Stratified flow over a mountain with a gap: Linear theory and numerical simulations. Q. J. R. Meteorol. Soc. 128: 927-949.

Zängl G. 2003. Deep and shallow south foehn in the region of Innsbruck: Typical features and semi-idealized numerical simulations. Meteorol. Atmos. Phys. 83: 237-262.

Zängl G. 2004. A reexamination of the valley wind system in the Alpine Inn Valley with numerical simulations. Meteorol. Atmos. Phys. 87: $241-256$.

Zängl G. 2005. Dynamical aspects of wintertime cold-air pools in an Alpine valley system. Mon. Weather Rev. 133: 2721-2740.

Zängl G, Hornsteiner M. 2007. The exceptional Alpine south föhn event of 14-16 November 2002: A case study. Meteorol. Atmos. Phys. in press.

Zängl G, Gohm A, Geier G. 2004. South föhn in the Wipp Valley - Innsbruck region: Numerical simulations of the 24 October 1999 case (MAP IOP 10). Meteorol. Atmos. Phys. 86: 213-243. 